\title{
Building Simulation
}

\section{THERMAL COMFORT ASSESSMENT OF A NEW DIFFUSER FOR AIR COOLING/HEATING SYSTEM: MEASUREMENTS AND NUMERICAL VALIDATION \\ --Manuscript Draft--}

\begin{tabular}{|c|c|}
\hline \multicolumn{2}{|l|}{ Manuscript Number: } \\
\hline Full Title: & $\begin{array}{l}\text { THERMAL COMFORT ASSESSMENT OF A NEW DIFFUSER FOR AIR } \\
\text { COOLING/HEATING SYSTEM: MEASUREMENTS AND NUMERICAL VALIDATION }\end{array}$ \\
\hline Article Type: & Research Article \\
\hline Corresponding Author: & $\begin{array}{l}\text { Laura Pompei, Ph.D. } \\
\text { Sapienza University of Rome: Universita degli Studi di Roma La Sapienza } \\
\text { ITALY }\end{array}$ \\
\hline \multicolumn{2}{|l|}{$\begin{array}{l}\text { Corresponding Author Secondary } \\
\text { Information: }\end{array}$} \\
\hline Corresponding Author's Institution: & Sapienza University of Rome: Universita degli Studi di Roma La Sapienza \\
\hline \multicolumn{2}{|l|}{$\begin{array}{l}\text { Corresponding Author's Secondary } \\
\text { Institution: }\end{array}$} \\
\hline First Author: & Fabio Nardecchia, P.h.D. \\
\hline \multicolumn{2}{|l|}{ First Author Secondary Information: } \\
\hline \multirow[t]{3}{*}{ Order of Authors: } & Fabio Nardecchia, P.h.D. \\
\hline & Laura Pompei, Ph.D. \\
\hline & Fabio Bisegna, Associate Professor \\
\hline \multicolumn{2}{|c|}{ Order of Authors Secondary Information: } \\
\hline \multicolumn{2}{|l|}{ Funding Information: } \\
\hline Abstract: & $\begin{array}{l}\text { Air distribution of HVAC systems is the most popular type used in the building sector, } \\
\text { having a relevant impact on indoor air quality and occupant wellness. The balance } \\
\text { between guaranteeing indoor thermal comfort and reducing energy consumption has } \\
\text { become a significant issue in the last years, especially connected to the building } \\
\text { construction. In line with this, this research investigates the potentialities of a new air } \\
\text { diffuser type, installed in the ceiling of an exhibition room. This system provides a } \\
\text { variable mass flow rate thanks to its configuration, allowing to determinate a good } \\
\text { thermal comfort. A warm wall is chosen as the heating system. Several tests are } \\
\text { carried out, six for cooling and two for heating with different volumetric air rate and } \\
\text { supply air temperature of the diffusers. The combination of two methods, the } \\
\text { measurements campaigns and the Computational Fluid Dynamics techniques, allows } \\
\text { studying the thermal indoor environment. In general, results show a strong capability of } \\
\text { this diffuser to provide a uniform temperature and velocity field inside the room. } \\
\text { Moreover, experimental and numerical data are significantly comparable giving an } \\
\text { average deviation of } 1 \% \text { for the velocity and lower } 1 \% \text { for the temperature. According } \\
\text { to this, it is evident that the design of INDULINE allows to obtain optimal temperature } \\
\text { and velocity distribution on the vertical and horizontal planes. }\end{array}$ \\
\hline \multirow[t]{2}{*}{ Suggested Reviewers: } & $\begin{array}{l}\text { Francesco ASDRUBALI } \\
\text { Full Professor, Sapienza University of Rome: Universita degli Studi di Roma La } \\
\text { Sapienza } \\
\text { francesco.asdrubali@uniroma3.it } \\
\text { expert in the field }\end{array}$ \\
\hline & $\begin{array}{l}\text { Mojtaba Navvab } \\
\text { Associate Professor of Architecture, University of Michigan A Alfred Taubman College } \\
\text { of Architecture and Urban Planning } \\
\text { moji@umich.edu } \\
\text { expert in the field }\end{array}$ \\
\hline Opposed Reviewers: & \\
\hline
\end{tabular}


THERMAL COMFORT ASSESSMENT OF A NEW DIFFUSER FOR AIR COOLING/HEATING SYSTEM: MEASUREMENTS AND NUMERICAL VALIDATION

Fabio Nardecchia ${ }^{1}$,Laura Pompei ${ }^{1 *}$, Fabio Bisegna ${ }^{1}$

${ }^{1}$ Department of Astronautic, Electric and Energy Engineering

Sapienza University, Via Eudossiana 18 Rome, Italy

e-mail: fabio.nardecchia@uniroma1.it; laura.pompei@uniroma1.it; fabio.bisegna@uniroma1.it

* Corresponding author, email: laura.pompei@uniroma1.it 
Keywords: CFD, field measurements, INDULINE, HVAC systems, thermal comfort

\begin{abstract}
Air distribution of HVAC systems is the most popular type used in the building sector, having a relevant impact on indoor air quality and occupant wellness. The balance between guaranteeing indoor thermal comfort and reducing energy consumption has become a significant issue in the last years, especially connected to the building construction. In line with this, this research investigates the potentialities of a new air diffuser type, installed in the ceiling of an exhibition room. This system provides a variable mass flow rate thanks to its configuration, allowing to determinate a good thermal comfort. A warm wall is chosen as the heating system. Several tests are carried out, six for cooling and two for heating with different volumetric air rate and supply air temperature of the diffusers. The combination of two methods, the measurements campaigns and the Computational Fluid Dynamics techniques, allows studying the thermal indoor environment. In general, results show a strong capability of this diffuser to provide a uniform temperature and velocity field inside the room. Moreover, experimental and numerical data are significantly comparable giving an average deviation of $1 \%$ for the velocity and lower $1 \%$ for the temperature. According to this, it is evident that the design of INDULINE allows to obtain optimal temperature and velocity distribution on the vertical and horizontal planes.
\end{abstract}

\title{
1. Introduction
}

One of the most important issues in building design is to optimize the dimensions and productivity of the space and contemporarily to guarantee a healthy and comfortable area for inhabitants (Kima e al. 2013). Many factors are involved in the creation of a high-quality indoor environment such as air quality, thermal, acoustic and lighting comfort; among these, one of the most important aspect is the control of thermal conditions. Concerning the space heating and cooling, especially in public buildings, the most common way to provide air temperature and manage air ventilation is to use HVAC systems, which come to be the biggest energy consumer in buildings with a percentage up to $60 \%$, as showed in several works (Chen et al. 2018, Dai et al. 2016). In line with this, HVAC systems was deeply investigated (Li et al. 2017, Zhang et al. 2019), underling its potentialities and ways of its optimizations.

Building construction is indeed the largest consuming sector: energy consumption of buildings is predicted to increase of about $70 \%$ by 2050 according to current trends ( $\mathrm{Li}$ and $\mathrm{Li} 2018$ ) and in these figures public buildings occupy the dominant position of energy consumption (Jiang 2011). Last but not least, climate change and global warming have become a serious issue to oppose, which cause an increase in frequency and magnitude of extreme climate events, as underlined (Muthers et al. 2017, Tan 2009) and in turns an increase of building cooling consumptions (Zinzi et al. 2018, Kovacs et al. 2018). 
According to this, the balance between guaranteeing indoor thermal comfort and reducing the Air distribution of HVAC systems strongly impact on, layout of indoor spaces, space organization, building construction costs and, above all, on indoor air quality (Kima e al. 2013). The design and operation of HVAC systems are strongly related to the indoor environmental quality and this issue is widely studied (Che et al. 2019) for different contexts (offices, houses etc.).

Main strategies proposed in literature to optimize demand, supply and consumption of HVAC systems regard: the design of centralized strategy for indoor environmental responses and energy consumption based on linear models (Ren and Cao 2019, Ascione et al. 2013); the application of control zoning strategies to create flexible space layout designs, examined by (Gärtner et al. 2020); the provision of Human-In-The-Loop (HITL) operations, which are based on information from human interactions, occupants needs and occupancy-related features, as relevant scientific contributions highlight (Junga, and Jazizadehb 2019, Li 2020) the improvement of HVAC systems' efficiency and the optimization of the design of the air distribution system.

Many research are available in literature proposing optimal solutions for the design of HVAC systems, focusing on specific components of the distribution system (Gao et al. 2018), on the airflow and geometry of ducts (Manuel et al. 2018); on the size of ducts and fan (Fong et al. 2011, Jorens et al. 2018) on the shape and position of air diffusers (Aziz et al. 2012, Tacutu et al. 2019).

This research paper is a contribution of the latter research field. The air swirl diffusers are one of the most popular type used in air-conditioning systems. Literature studies confirm their higher potential compared to other models of diffusers.

The airflow features of different shape of diffusers (vortex or swirl, round, and square) were investigated (Aziz et al. 2012) by experimental and numerical analysis; on the other hand, two types of orifices for ceiling plan diffusers were investigated (Tacutu et al. 2019) worth numerical simulation and PIV stereotypic. It was found that the lobbed one can provide a better air distribution, influencing positively the thermal stratification. The performance of air swirl diffusers characterized by different blades' angles were analysed in (Jaszczur et al. 2016, Pandey et al. 2015).

In this framework, this research aims to study a new linear wall diffuser with a variable mass flow, named INDULINE. Aforementioned studies focused either on the energy performance of the analysed diffusers or on one/two thermo-hygrometric variables (namely humidity and temperature). Accordingly, two parameters, the velocity and the temperature, are analysed in this work both useful for defining the indoor comfort. This evaluation is carried on through the measurements campaigns and the Computational Fluid Dynamics (CFD) techniques, chosen an exhibition room as a case study. The comparison of the two methods, the experimental and numerical (CFD) analysis, show up their reliability and accuracy. Both heating and cooling results are discussed and compared each other to globally describe the functioning of the air diffusers. Moreover, results demonstrated that the innovative design of this swirl diffuser provides a good capability in guaranteeing uniformity of temperature and velocity field, essential for the occupant comfort.

The presented work is divided into four macro sections. Following the Introduction, the Materials and methods paragraph describes the used diffuser and the entire set-up process of this analysis. The third section is focused on the results wherein authors point out the advantages and potentialities of 
this diffusor based on the experimental and numerical results. Conclusions were placed in the last section of this paper highlighting the usefulness of this research project. Understood that this work represents the first analysis of this new type of diffuser, future developments will involve the analysis of another hygrometric parameter, the relative humidity.

\section{Materials and methods}

In this section, a brief description of the employed diffuser is proposed. "INDULINE" is a linear wall diffuser with a variable mass flow, not operating at a constant rate. This diffuser is characterized by a modern and integrated design as showed in Figure 1a. Moreover, the dimension of the diffuser is flexible, and it can be adaptable depending on the usage.
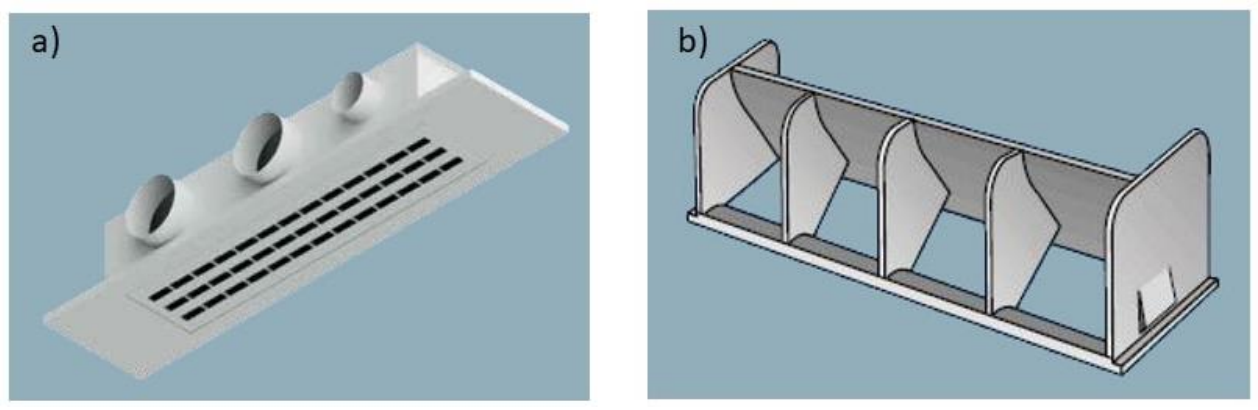

Figure 1-a) INDULINE diffuser; b) Micro spot diffuser (C20)

More in details, the supply diffuser has a rectangular section, and it is composed of one or two rows of micro spot diffusers (Figure 1-b) with also a rectangular shape and arranged vertically (INDULINE data sheet). The micro spots (typology of C20) are made in antistatic plastic material which is also UV resistant (colour RAL 7035). The entry plate, sized $900 \times 200 \mathrm{~mm}$ with rectangular section, is hinged with a push-push release and possibly removable to facilitate access to the plenum. The latter, it prepared using galvanized steel and it is insulated externally with foam rubber sheets class 1. Finally, it is furnished with circular connections.

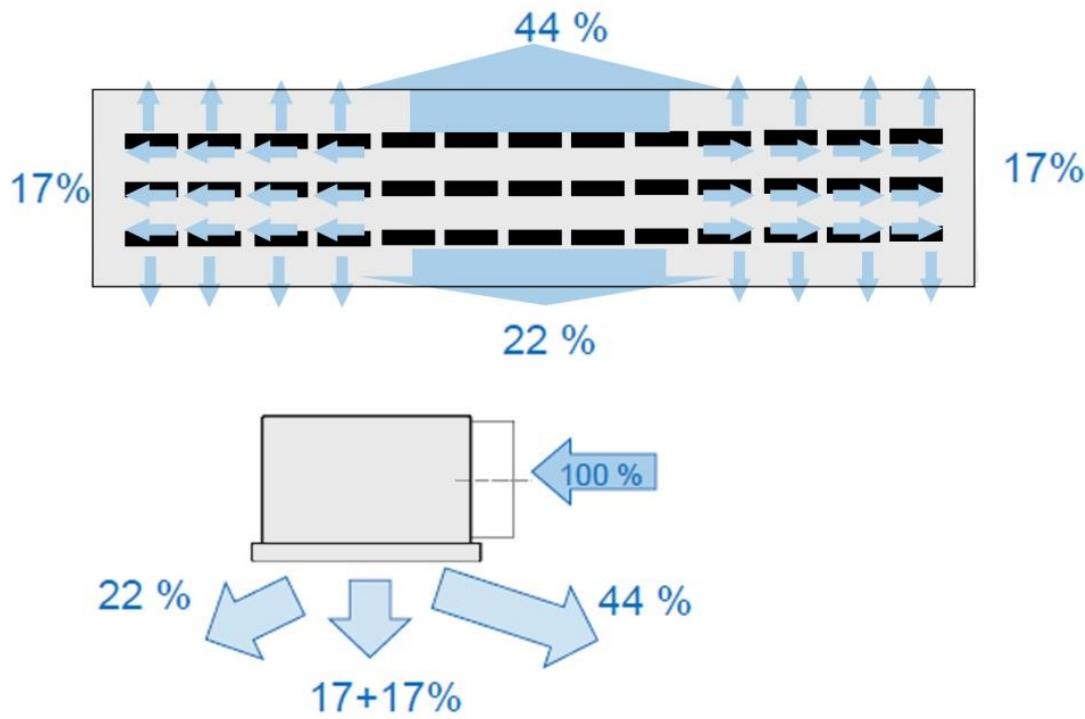

Figure 2 - INDULINE diffuser- functioning 
On the other hand, thermal and acoustic comfort is guaranteeing thanks to its functioning. Figure 2 shows the percentage of mass flow for each side of the diffuser. A constant mass flow rate is avoided, allowing the device to differently distributed the air in the room. This configuration is optimal for individuals comfort, as is demonstrated in the following paragraphs.

\subsection{Experimental set-up}

The experimental tests were carried out by the Kiefer company, in collaboration with the company SAGICOFIM S.p.a., at their laboratories in Stuttgart, Germany.

The dimensions of the test room in which the measurements took place were $\mathrm{L}=4.50 \mathrm{~m}, \mathrm{~W}=4.50$ $\mathrm{m}, \mathrm{H}=2.80 \mathrm{~m}$. (see Figures 3 and 4). The air diffuser INDULINE was installed into a mineral fibre ceiling with a visible support structure. To avoid exchange of heat to or from the test room the anteroom was constantly kept at the same temperature level as the test room. Norms conform dummies were employed to simulate the presence of people in the room. The warm façade was simulated with smooth surface radiation at the back side of the test room. The water supply temperature to the radiator was variated for each case to ensure the correct heating capacity (thermal load). On the roof, there are installed two air diffuser INDULINE for the supply air and other two for the recovery of exhausted air. Those two air supply diffusers present a distance of $1.35 \mathrm{~m}$ between them and they are located at $2.05 \mathrm{~m}$ from the recovery of exhausted air ones (Figure 4). Figure 4 reports some of the total measurement points to show their location in the room but, at the same time, to propose a clear representation to the readers. The warm wall surface is 4.5 $\mathrm{m}^{2}$ and it is located near the air supply diffusers.

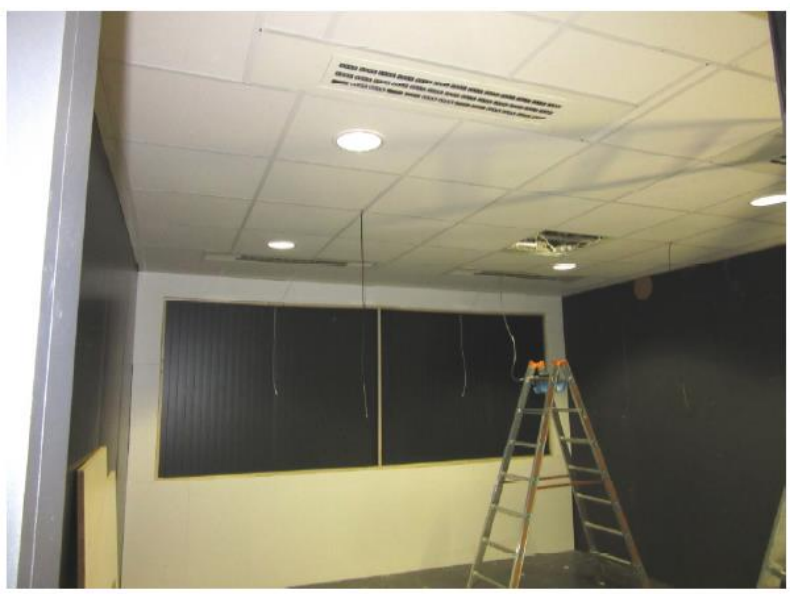

a)

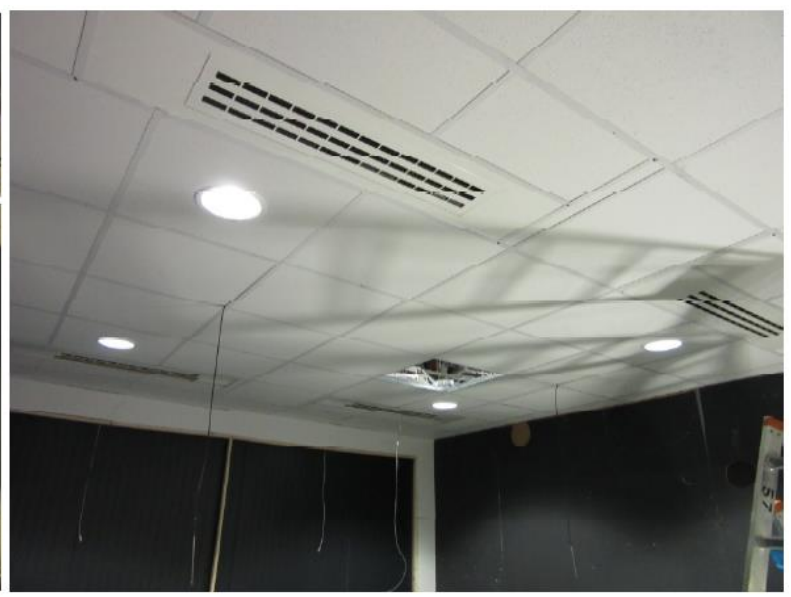

b)

Figure 3-Room set up 
Air velocity and air temperature were measured with anemometer probes at 30 points in the test room. The measuring grid between the individual measuring points was $1 \mathrm{x} 1 \mathrm{~m}$ which corresponds to 30 measuring points in total, according to standard for measurements (UNI EN ISO 7730, 2006), determination, and interpretation of thermal comfort in the occupied zone. As aforementioned, the measurements points are chosen to analysed the comfort inside the room. Points located under the supply and recovery diffusers are not considered in this study, therefore they are excluded.

The sensors to determine the thermal comfort were installed at $0.1 \mathrm{~m}, 1.1 \mathrm{~m}$, and $1.8 \mathrm{~m}$ height.

The accuracy of velocity measurement is $\pm 0.06 \mathrm{~m} / \mathrm{s}$ for the range of $0.05-5 \mathrm{~m} / \mathrm{s}$ and the accuracy of temperature measurement is $\pm 0.2{ }^{\circ} \mathrm{C}$. Figure 4 shows an example of the probes placement in the room.

A total of eight different test cases were tested (six cooling cases and two heating cases) and the characteristics for each case are shown in Table 1:

\begin{tabular}{|c|c|c|c|c|}
\hline Test Case & $\begin{array}{c}\text { Thermal load } \\
{\left[\mathbf{W} / \mathbf{m}^{2}\right]}\end{array}$ & $\begin{array}{c}\text { Supply air } \\
\text { temperature } \\
{\left[{ }^{\circ} \mathbf{C}\right]}\end{array}$ & $\begin{array}{c}\text { Room air } \\
\text { temperature } \\
{\left[{ }^{\circ} \mathbf{C}\right]}\end{array}$ & $\begin{array}{c}\text { Volumetric air rate } \\
(\text { for each diffusor) } \\
{\left[\mathbf{m}^{\mathbf{3}} / \mathbf{h}\right]}\end{array}$ \\
\hline $\mathbf{T C 1}$ & $100 \%-105$ & 11 & 24 & 315 \\
\hline $\mathbf{T C 2}$ & $70 \%-90$ & 17 & 25 & 315 \\
\hline
\end{tabular}




\begin{tabular}{|c|c|c|c|c|}
\hline TC3 & $30 \%-70$ & 21 & 26 & 315 \\
\hline TC4 & $50 \%-80$ & 12 & 25 & 195 \\
\hline TC5 & $50 \%-80$ & 12.5 & 25 & 145 \\
\hline TC6 & $50 \%-80$ & 12 & 25 & 145 \\
\hline TC7 & heating case & 24.7 & 22.7 & 210 \\
\hline
\end{tabular}

Table 1 - Versions tested

\subsection{Numerical simulation procedure}

\subsubsection{Governing equations and turbulence model}

In this study, the three-dimensional Reynolds-Averaged Navier-Stokes (RANS) equations are the governing equations of the turbulent compressible fluid flow, with not constant thermophysical properties. Ansys Fluent solves the balance equations of mass and momentum and additional transport equations related to closure assumptions. These three governing equations can be expressed as:

$$
\begin{gathered}
\frac{\partial \bar{u}_{i}}{\partial x_{i}} \quad \mathrm{i}=1,2,3 \\
\bar{u}_{j} \frac{\partial \bar{u}_{i}}{\partial x_{j}}=-g_{i}-\frac{1}{\rho} \frac{\partial \bar{p}}{\partial x_{i}}+\frac{\partial}{\partial x_{j}}\left[v \frac{\partial \bar{u}_{i}}{\partial x_{j}}-\overline{u_{l}^{\prime} u_{J}^{\prime}}\right] \quad \mathrm{i}=1,2,3 \\
\bar{u}_{j} \frac{\partial \bar{T}}{\partial x_{i}}+\frac{\partial}{\partial x_{i}}\left(K_{T} \frac{\partial \bar{T}}{\partial x_{i}}\right)=0 \quad \mathrm{i}=1,2,3
\end{gathered}
$$

where $\bar{u}_{i}$ is the components of the mean velocity, $\bar{p}$ the mean pressure, $g_{i}$ the gravitational acceleration and $\bar{u}_{i} \bar{u}_{j}$ the Reynolds stress tensor, $\bar{T}$ the mean temperature, $K_{T}$ is the thermal conductivity. Generally, the Reynolds stress tensor is modelled considering a linear proportionality to the rate of strain (Boussinesq eddy viscosity model):

$$
-\overline{u_{\imath}^{\prime} u_{\jmath}^{\prime}}=\frac{\mu_{t}}{\rho}\left(\frac{\partial \bar{u}_{i}}{\partial x_{j}}+\frac{\partial \bar{u}_{j}}{\partial x_{i}}\right)-\frac{2}{3} \delta_{i j} k
$$


where $k$ is the turbulent kinetic energy, $\mu_{t}$ the eddy (or turbulent) viscosity and $\delta_{i j}$ the Kronecker delta.

The $\mathrm{k}-\varepsilon$ model was chosen as turbulence model since it is the most common turbulence model employed in CFD codes. It solves the Reynolds-Averaged Navier- Stokes (RANS) equations coupled with transport equations for the turbulent kinetic energy, $\mathrm{k}$, and its dissipation rate, $\varepsilon$. In this model, only the mean flow is solved, while turbulence is parameterized at all scales by means of suitable laws.

In this study, a modified version of the standard k- $\varepsilon$ model (Launder and Spalding, 1972), the RNG $\mathrm{K}-\varepsilon$ model, was used. The RNG $\mathrm{k}-\varepsilon$ model is derived using a rigorous statistical method called renormalization group (RNG). The RNG $\mathrm{k}-\varepsilon$ model is obtained using a rigorous statistical technique. It is similar in form to the standard $\mathrm{k}-\varepsilon$ model, but includes the following refinements: the RNG k- $\varepsilon$ model has an additional term in its equation in $\varepsilon$ which improves the accuracy for rapidly forced flows; the effect of swirling movement on turbulence is included, increasing accuracy for swirling flows; RNG theory provides an analytical formula for the turbulent Prandtl number, while the standard k- $\varepsilon$ model uses constant values set by the user; while the standard k- $\varepsilon$ model is valid for high Reynolds numbers, the RNG theory takes into account the effects of low Reynolds numbers.

These features make the RNG k- $\varepsilon$ model more accurate and reliable for a wider class of indoor airflows than the standard $\mathrm{k}-\varepsilon$ model.

It was found (Chen, 1999) that the RNG k- $\varepsilon$ model has the best performance for simulations of indoor airflow, compared to the other k- $\varepsilon$ models. He noted that the performance of the other models was not so stable. Also, international researchers groups (Rouaud and Havet, 2002, Gebremedhin and $\mathrm{Wu}, 2003$ ) showed that the RNG $\mathrm{k}-\varepsilon$ model predicts well the flow filed in confined spaces. They made a comparison with other RANS models and found an overestimation of turbulence diffusion for these models.

Regarding the thermal aspects, researchers (Cheong et al. 2003) pointed out that the RNG k-E model were in good agreement with experimental measurements, carried out with the software Fluent. Other studies (Stamou and Katsiris, 2006) compared experiments results with the results of

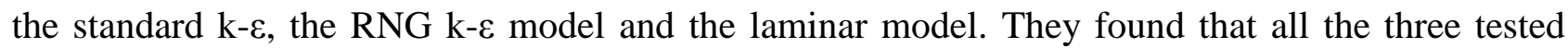
turbulent models predict with a good approximation the flow and the temperature fields.

\subsubsection{Solution methodology}

The commercial software Ansys Fluent v.14.5 (Stamou and Katsiris, 2006) was adopted to carry out the CFD steady simulations. The simulations were performed with 3D double precision solver with a pressure-based solver, in a steady-state regime. As described in the previous section, the RANS steady equations were used in combination with the RNG k- $\varepsilon$ model, and a second-order discretization scheme was chosen for the convection and viscous terms of the governing equations. Pressure-velocity coupling was developed using the PISO algorithm (ANSYS, 1994). 
When the sum of the residual values around the system reached a minimum of $10^{-5}$ for $\mathrm{x}, \mathrm{y}$ and $\mathrm{z}$ momentum, $\mathrm{k}, \varepsilon$, energy and continuity, the calculations were stopped, and the solution was considered converged. Variables of interest, like velocity and temperature, were controlled in several chosen points during the solving process to ensure they were monitored before the convergence occurred.

\subsubsection{Computational domain, grid and boundary conditions}

The form and component size of the computational domain and boundary conditions were modelled to be identical to the experiment. As shown in Figure 4, the computational domain is a rectangular prism with a square cross section of $4.50 \times 4.50 \mathrm{~m}$ and a height of $2.80 \mathrm{~m}$.

A uniform velocity field at the inflow was imposed, together with non-slip velocity conditions in all the walls. The water supply temperature to the radiator was varied for each case to ensure the correct heating capacity (thermal load), as specified in Table 1.

The boundary conditions were considered at constant temperature $\mathrm{T}_{\mathrm{a}}\left(26^{\circ} \mathrm{C}\right.$ for the cooling cases and $20{ }^{\circ} \mathrm{C}$ for the heating cases) on the roof and on the wall in which the diffuser terminal device was placed. Instead, the ground surface was considered adiabatic. Finally, at the exit plane a pressure-outlet boundary condition was applied with uniform zero relative pressure.

Unstructured tetrahedral cells were used to discretize the computational domain (Figure 5). A meshindependency study was performed on the TC1 using coarse, medium, and fine grids containing 1.8, 2.8 and 4.25 million cells, respectively.

For this mesh-independency study, the RNG k- $\varepsilon$ turbulence model was employed. The velocity in the middle of the domain was chosen as a parameter for the test. Assuming the finest mesh considered, Mesh C (mesh spacing equal to $0.1 \mathrm{~m}$ ), as the pivot case, it is possible to observe that the difference percentage $\Delta \%$ with Mesh A (mesh spacing equal to $0.05 \mathrm{~m}$ ) is only $3.15 \%$. Almost equal results were obtained for other monitor points on the other positions of the domain.

As the Table 2 shows, the grid A can be selected as the best grid resolution because further increasing the cell numbers has no evident improvements in the numerical results and it only increases the computational cost. Therefore, Mesh A was used for these CFD analyses (Table 2).

\begin{tabular}{cccc}
\hline & Mesh A & Mesh B & Mesh C \\
\hline Cells of the mesh [-] & $\sim 2 \cdot 800 \cdot 000$ & $\sim 1 \cdot 800 \cdot 000$ & $\sim 4 \cdot 250 \cdot 000$ \\
Mesh spacing [m] & 0.1 & 0.2 & 0.005 \\
$\begin{array}{c}\Delta \% \text { on velocity [-] } \\
\text { GCi [\%] }\end{array}$ & 3.15 & 15.72 & - \\
\hline
\end{tabular}

Table 2 - Mesh sensitivity test 
Moreover, the grid convergence index (GCI) was investigated, in order to estimate the convergence of the grid refinement (Issa, 1986). The equation (5) gives the value of the order of convergence p:

$$
p=\frac{\frac{\ln \left[\varphi_{\text {medium }}-\varphi_{\text {coarse }}\right]}{\varphi_{\text {fine }}-\varphi_{\text {medium }}}}{\ln (r)}
$$

where $\varphi_{\text {coarse }}, \varphi_{\text {medium }}$ and $\varphi_{\text {fine }}$ are the average air velocity at the coarse, medium and fine grids, respectively. The grid refinement ratio, $r$, is calculated using the following equation (Issa, 1986):

$$
r=\left(\frac{N_{\text {fine }}}{N_{\text {medium }}}\right)^{1 / D}
$$

where $\mathrm{N}$ is the cell count and $\mathrm{D}$ is the number of dimensions. The GCI is determined using the formula (7):

$$
G C I=\frac{\epsilon}{r^{p}-1}
$$


Where:

$$
\varepsilon=\left|\frac{\varphi_{\text {fine }}-\varphi_{\text {medium }}}{\varphi_{\text {fine }}}\right|
$$

The CGI values obtained are shown in Table 2. As can be seen in the table, the values of the CGI are less than $1 \%$ which confirms that the numerical results are grid independent (Issa, 1986).

\section{Results and discussion}

For the accurate evaluation of the INDULINE diffuser, both the thermal characteristics and airflow distribution will be examined. In this section, the authors will show the results obtained based on the experimental conditions, reported in Table 1. The results of the velocity and temperature variables, both measured in the chosen points, are the core of the presenting discussion, comparing them with the numerical simulations. Moreover, to analyse the uniformity of those variables varying the height to the ground and the relative user's comfort inside the room, the authors highlight results for planes parallel at heights of $0.1,1.1$ and $1.8 \mathrm{~m}$. Those three heights used for the experimental and simulation comparison are extremely relevant to study the human comfort, as significant researches demonstrate (Stamou and Katsiris, 2006).

Then, a comparison will be done between experimental and numerical results of velocity and temperature profiles along control lines, perpendicular to the floor and passing to specific regions of the room (Figure 4).

\subsection{Flow field calculations}

Figure $6(a, b)$ shows the experimental tests results at various heights above the ground. For each case, the velocity data, registered in the measured points, are obtained using interpolation procedures. The airflow does not change with the height, remaining the same along the three heights for all the cases, so the head-foot discomfort of the occupants is therefore absent in those configurations._More in details, the cases TC1 and TC6, involving the cooling option, present vortex effects near the supply air diffusers, but considering the absolute value of those phenomena, they are equal to the surrounding zones. The mean velocity is attested to $0.15 \mathrm{~m} / \mathrm{s}$ for the TC1 case, wherein the outlet airflow is maximum, and it decreases to $0.10 \mathrm{~m} / \mathrm{s}$ in the case TC6, wherein the outlet airflow is minimum.

It is also evident that some air re-circulation zones characterized by higher and lower velocity respect to the mean one. However, the velocity difference in those vortexes is between 0.1 and 0.2 $\mathrm{m} / \mathrm{s}$, allow to guarantee the correct comfort for the occupants.

Lastly, the heating cases (TC7-TC8) demonstrate the uniformity of the velocity field varying the height. In those scenarios, the field uniformity is also extended to the entire room and the mean velocity deviation is above the value of $\pm 0.05 \mathrm{~m} / \mathrm{s}$. 
1

2

3

4

5

6

7

8

9
10

11

12

13

14

15

16

17

18

19

20

21

22

23

24

25

26

27

28

29

30

31

32

33

34

35

36

37

38

39

40

41

42

43

44

45

46

47

48

49

50

51

52

53

54

55

56

57

58

59

60

61

62

63

64

65
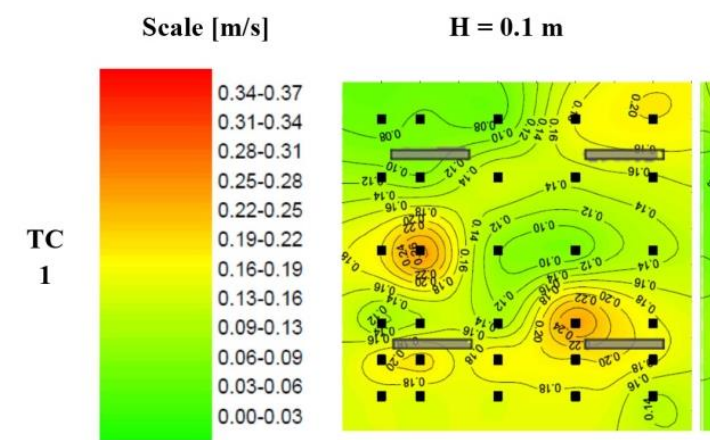

$\mathrm{H}=1.1 \mathrm{~m}$

$\mathrm{H}=1.8 \mathrm{~m}$
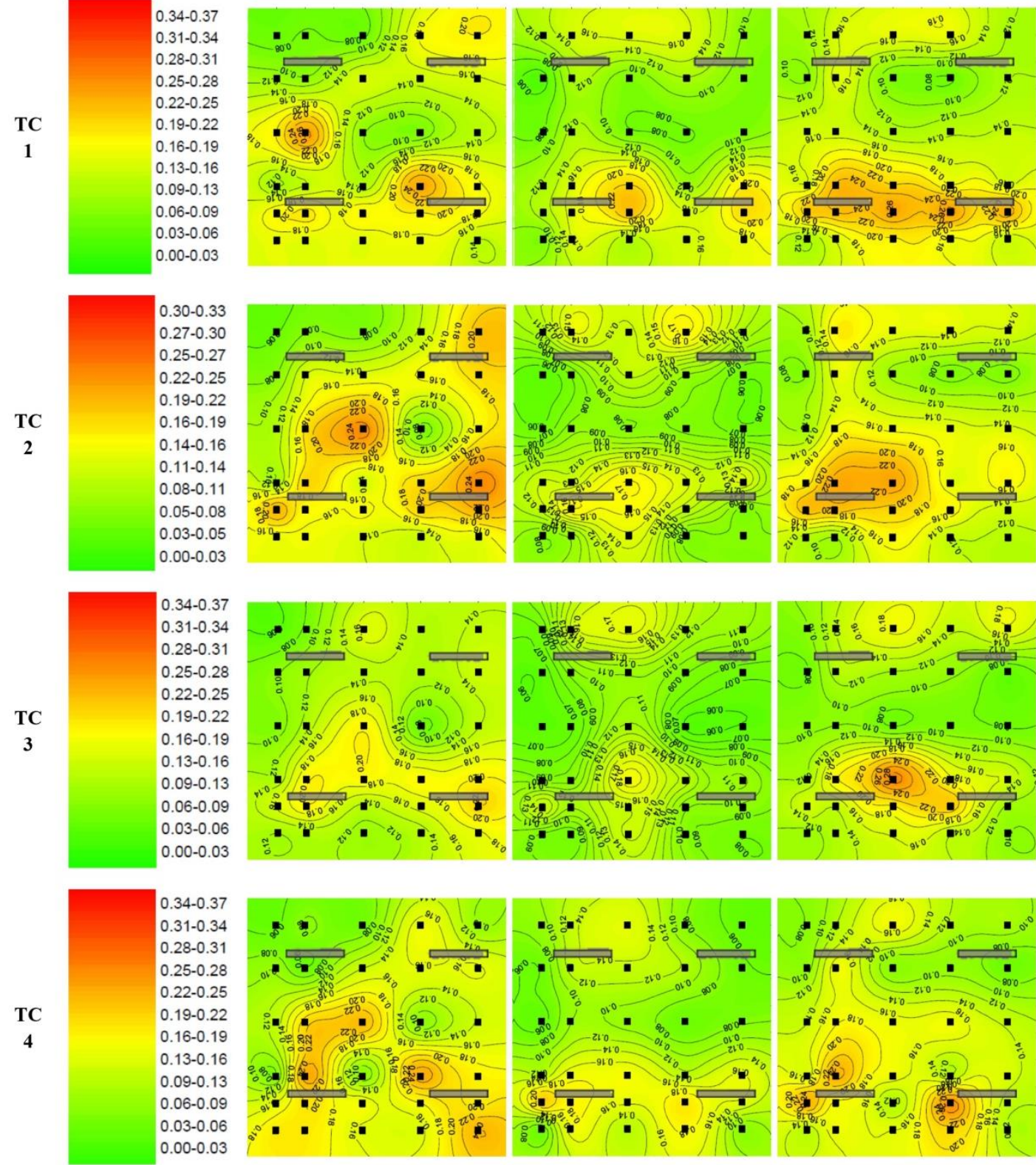

a) 
As aforementioned, the experimental velocity data are available only in the measured points, the velocity of the field is elaborated using interpolation methods. Consequently, the adoption of numerical fluid dynamic (CFD) simulations is essential to understand the trend in all the room points. Figure 7 reports the numerical simulations results using the same parallel planes (those plans are parallel to the floor with three different heights $0.1,1.1 \mathrm{e} 1.8 \mathrm{~m}$ ) adopted for the experimental data calculation. A similar trend is pointed up for heating cases, but with different average values (an overestimated values between $0.02-0.04 \mathrm{~m} / \mathrm{s}$ ). There are some zones characterized by high velocity near the air diffusers. Even though the numerical data in figure 7 allow to notice a huge air mass moving, the velocity values are quite low. Those movements are condensed near the warm 
wall, due to the development of hot air and its upwelling, providing instability in the considered zone.

Scale
$[\mathrm{m} / \mathrm{s}]$

TC1
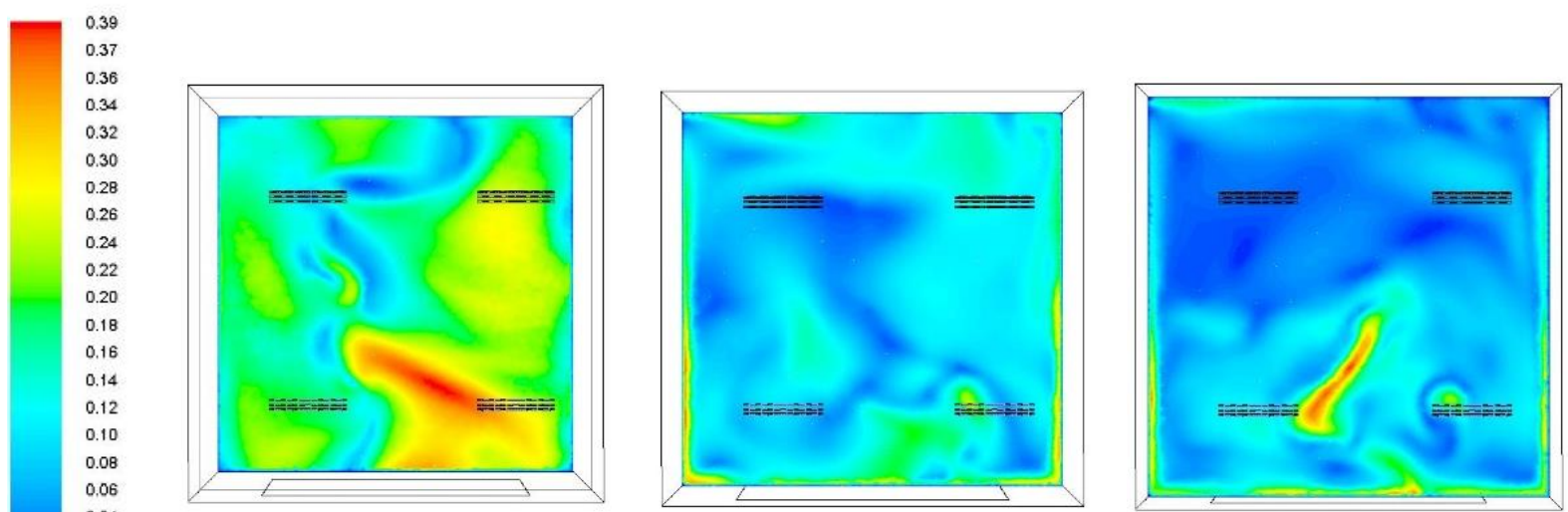

TC2
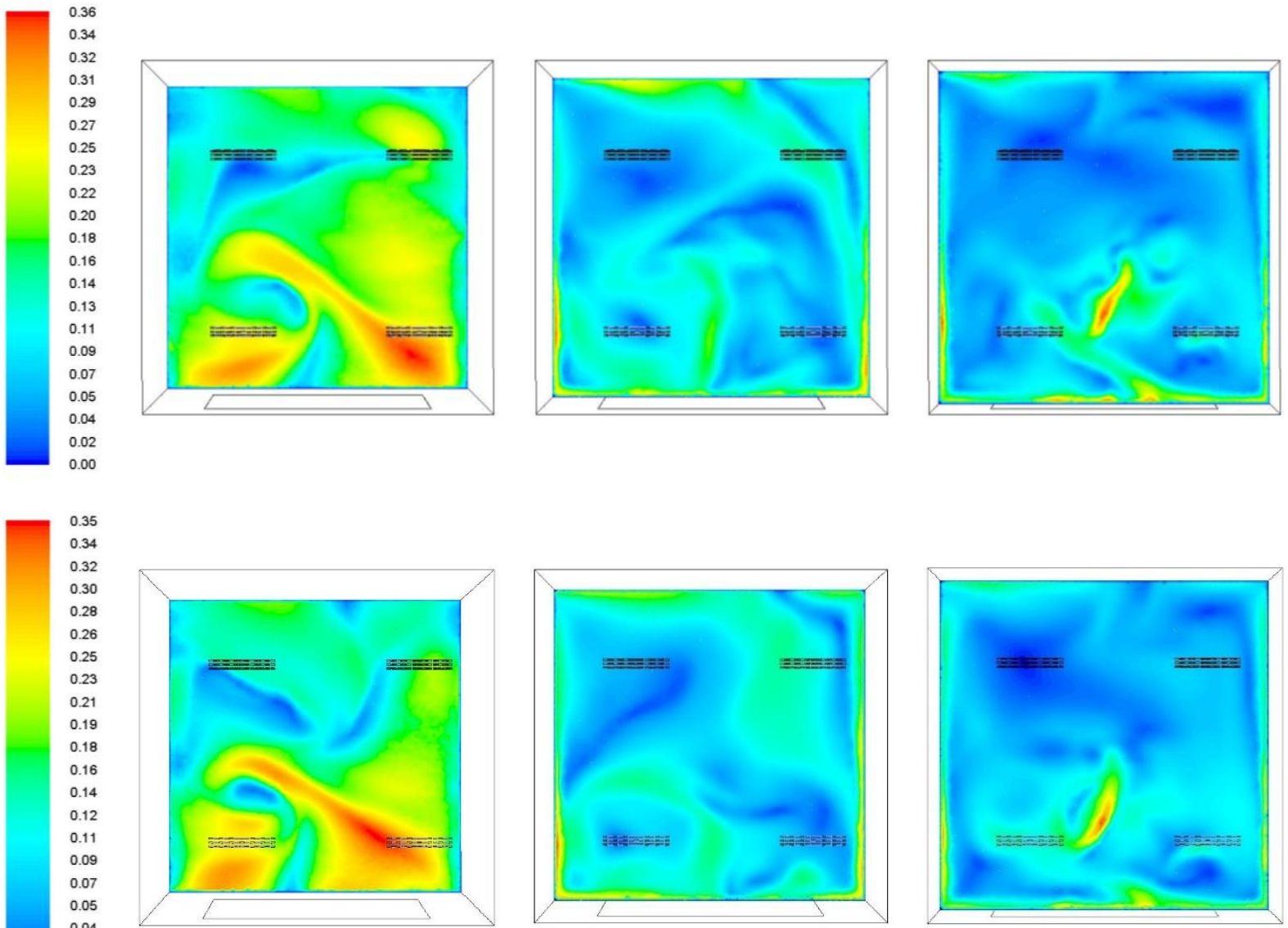


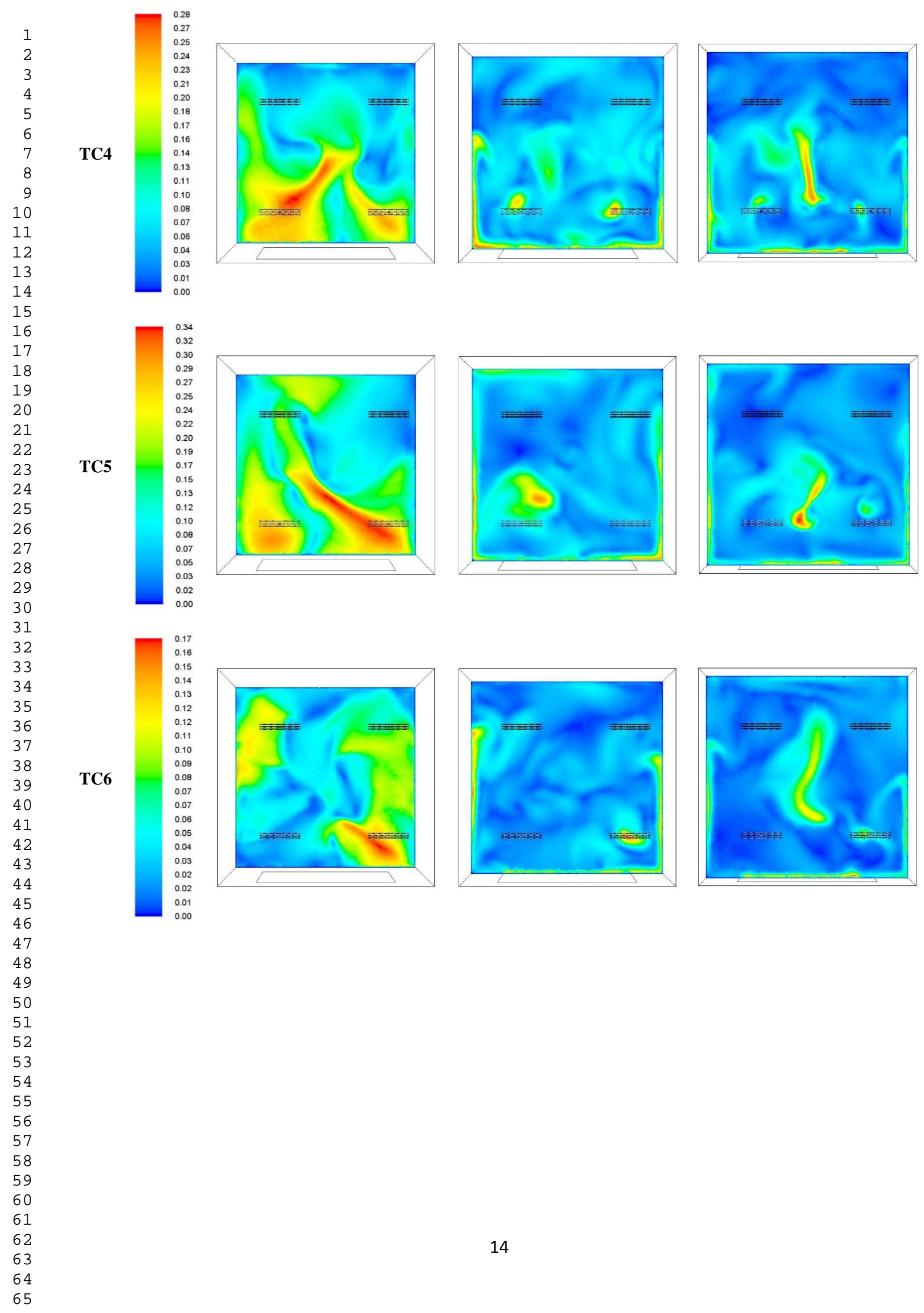



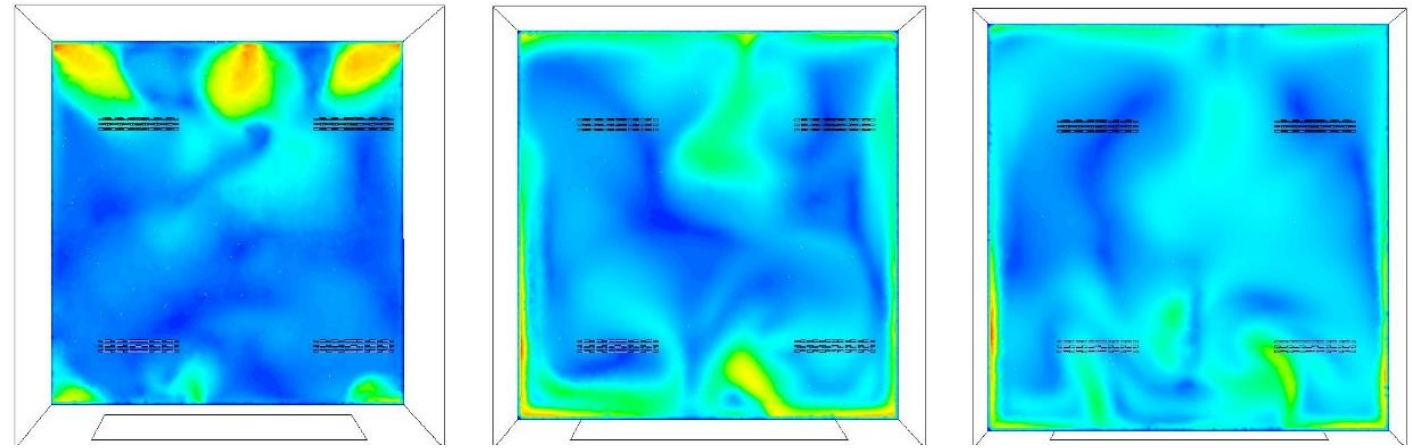

TC8
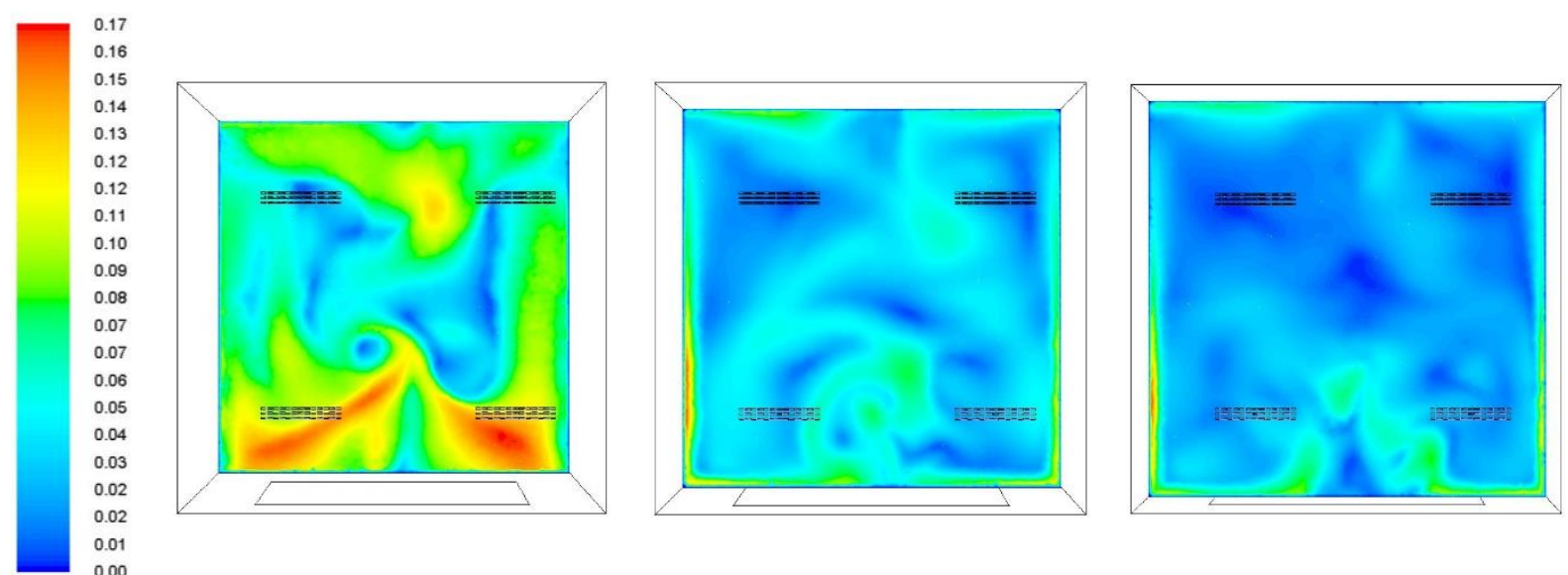

Figure 7 - Velocity contours at height 0.1, 1.1, $1.8 \mathrm{~m}$ from the ground

In Figures 8-11 it is reported the velocity vectors and contours into a plane parallel to the warm façade and passing in the inlet air diffusers. More in details, only Test Case 1 for the heating option and Test Case 8 for the cooling one are analyzed, being the cases with the extreme conditions both relating to the mass and the temperature.

From the analysis of the extracted images for this plan, there is a velocity uniformity in the test room, up to a certain height above the floor. The zones near the outlet air diffusers are visible, wherein the velocity is consistent, but it dissipates it force in a reduced space. The above zones, showed in Figures 8-9, reaches the velocity values acceptable for an occupant. The INDULINE diffusers, therefore, allow guaranteeing a good uniformity of the air velocity from the base to the top, providing the proper comfort for the occupants. 


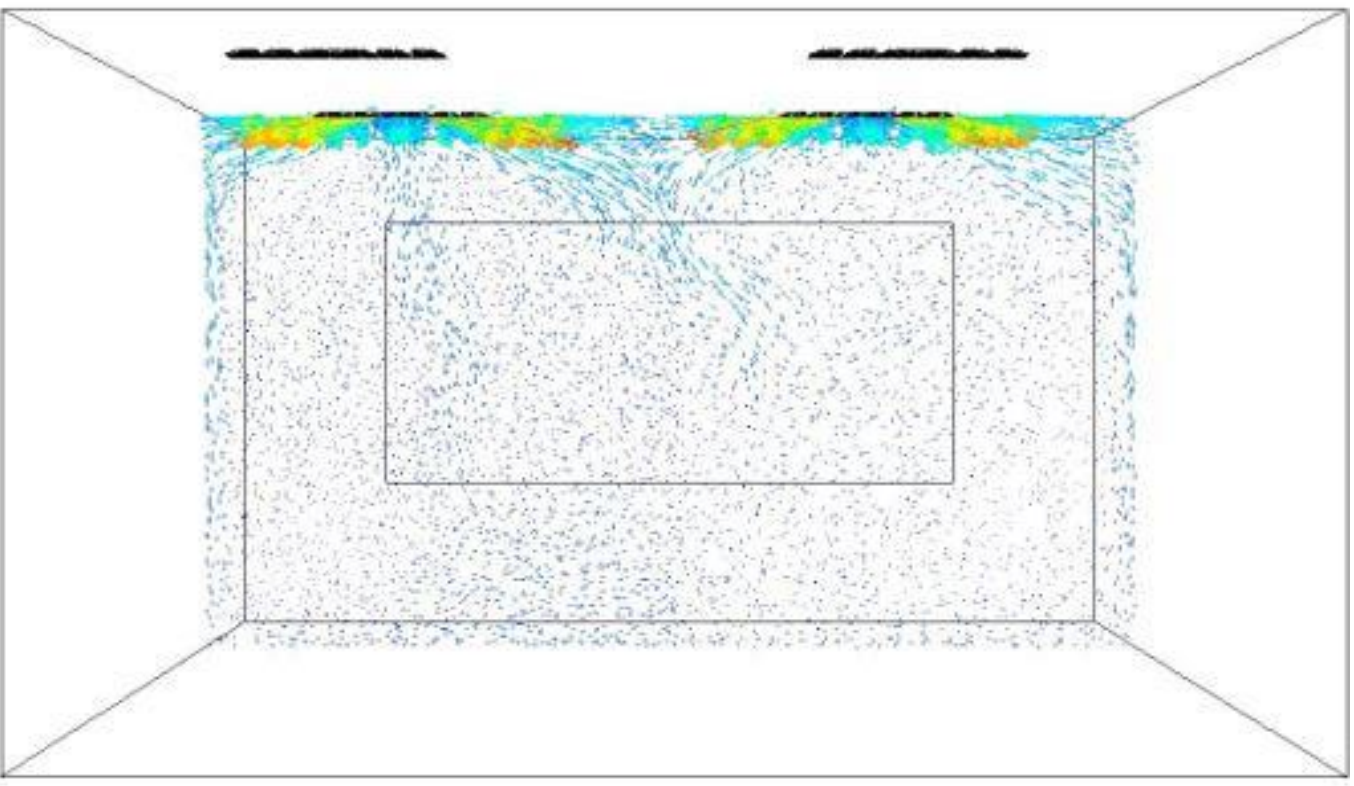

Figure 8 -Velocity vectors Test Case 1 - Plane $x=0.85 \mathrm{~m}, y=1.05 \mathrm{~m}$

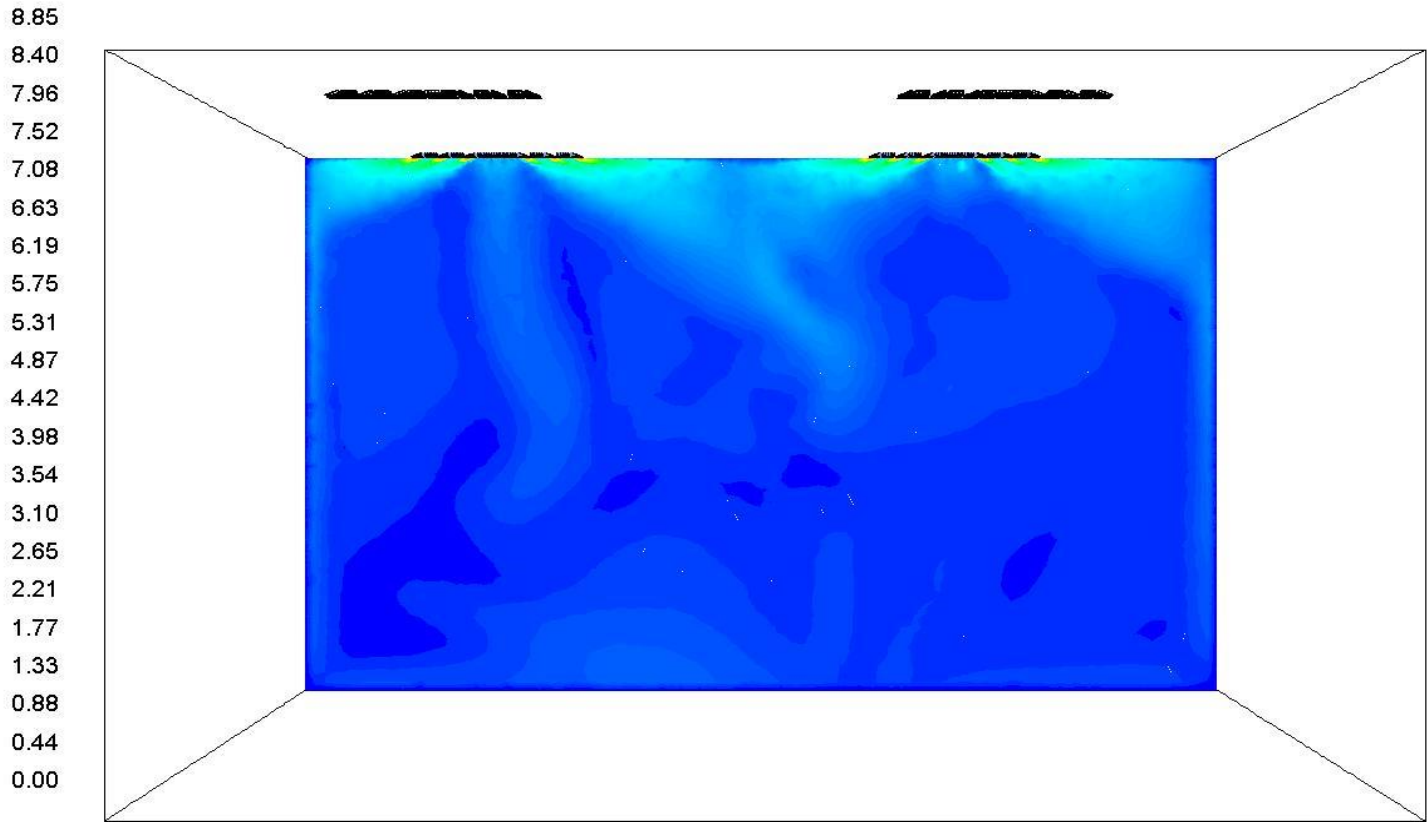

Figure 9 -Velocity contours Test Case $1-$ Plane $x=0.85 \mathrm{~m}, y=1.05 \mathrm{~m}$ 


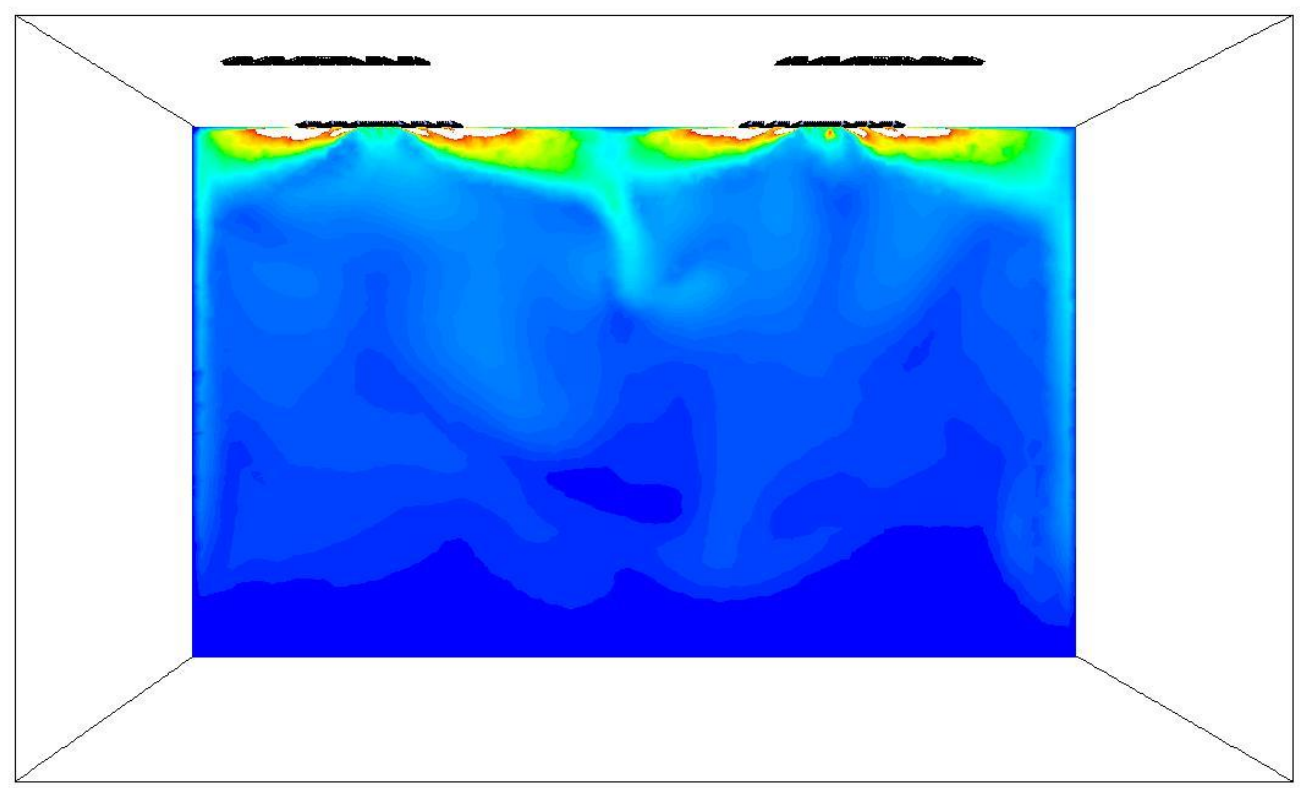

Figure 10 - Velocity vectors Test Case 8 - Plane $x=0.85 \mathrm{~m}, y=1.05 \mathrm{~m}$

Figure 12 reports the comparison between the experimental data obtained with the numerical simulations along specific vertical lines passing through:

- the centre of the room $(\mathrm{x}=1.5 \mathrm{~m}, \mathrm{y}=1.3 \mathrm{~m})$;

- the inlet air diffuser ( $x=2.5 \mathrm{~m}, \mathrm{y}=2.3 \mathrm{~m})$;

- the recovery air diffuser $(x=3.5 \mathrm{~m}, \mathrm{y}=3.8 \mathrm{~m})$. 
The blue points represent the numerical data, and the red triangles are the experimental data. Thanks to this comparison, two elements have to be discussed: the first one regards the similitude between the numerical and experimental data, except isolate case. This fact clearly underlines the fidelity of the numerical calculation of respect to the experimental one. The second consideration is related to the velocity uniformity of the field varying the height. The trends are constantly moving from the floor to the ceiling. Therefore, no consistent air movements are registered to allow to define this diffuser an optimal one able to provide the occupant's comfort in all the zones of the test room. In line with this, varying the height does not provoke annoying air velocity and directions changes.

The percentage error between experimental and numerical results is globally low. In details, the $\mathrm{TC} 1$ and TC2 average deviation is around $1-2 \%$, with a peak of $5 \%$ for the points located near the recovery air diffuser. Differently, the maximum variation of the two methods is set in correspondence of the inlet and outlet air (7\%) for the TC3 e TC4 tests, especially at the height of $0.1 \mathrm{~m}$ from the floor. The differences in the centre of the room, instead, are almost zero and the percentage error is lower than the $1 \%$. Noticeable differences are registered for the TC5 at a height of $1.8 \mathrm{~m}$ because the volumetric air rate is higher than the TC4 one. Therefore, it is more influenced by the diffusers presence. The TC6 shows considerable deviations in the vicinity of the recovery air diffusers, attested over 10\% for low heights above the ground, even though the volumetric air rate is less than the other cases. This issue is related to the high-temperature difference between the supply air temperature and room one, creating convection currents more intense.

Regarding the heating cases, TC7 and TC8, the percentage error starts from a value of $0.5 \%$ to higher values, moving from the inlet air diffusers to the recovery air one. Those differences reach up to $40 \%$ in the middle of the test room and under the diffuser, especially at the high heights. In this zone, the velocity is drastically decreased up to the order of $0.05 \mathrm{~m} / \mathrm{s}$. Moreover, the anemometers used are not able to measure those lower values of speed.
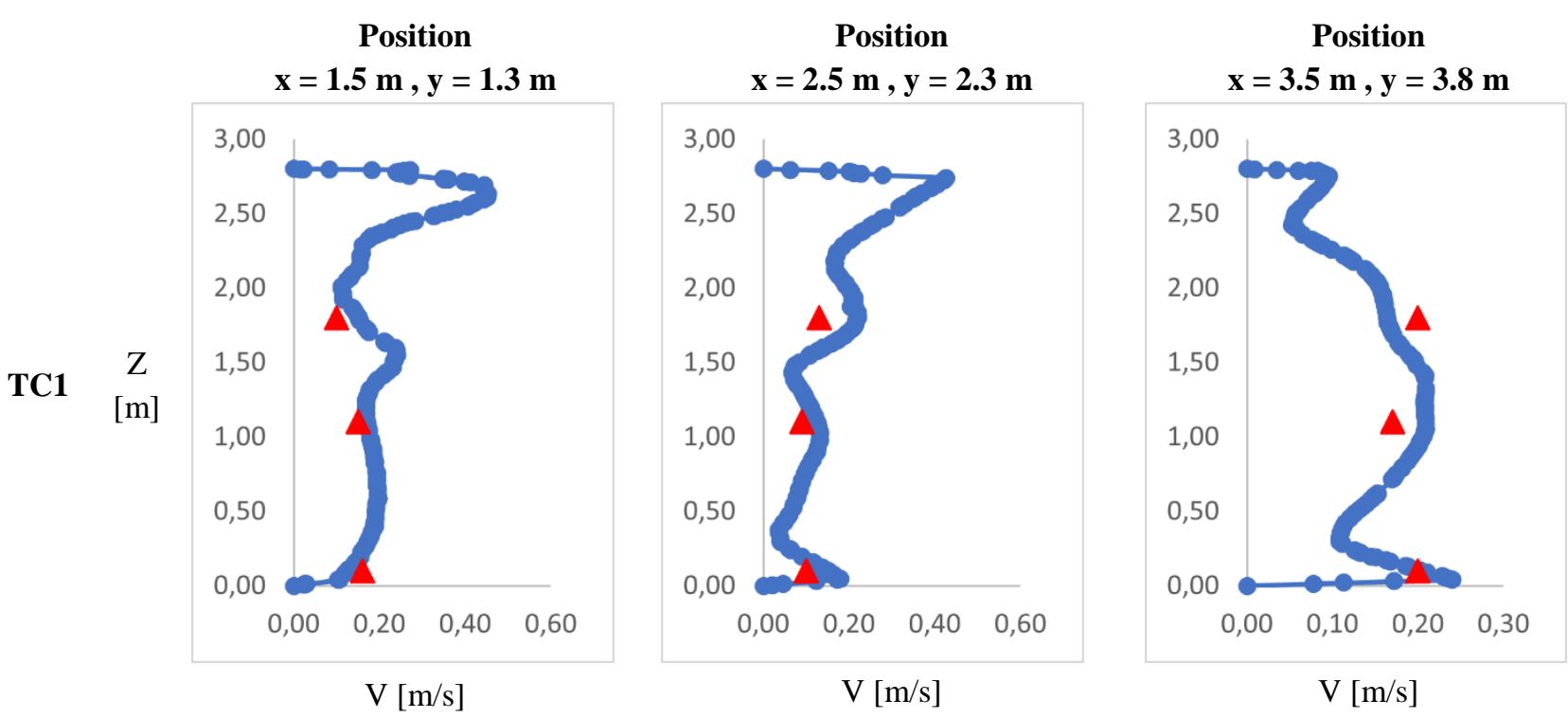
1

2

3

4

5

6

7

8

9

10

11

12

13

14

15

16

17

18

19

20

21

22

23

24

25

26

27

28

29

30

31

32

33

34

35

36

37

38

39

40

41

42

43

44

45

46

47

48

49

50

51

52

53

54

55

56

57

58

59

60

61

62
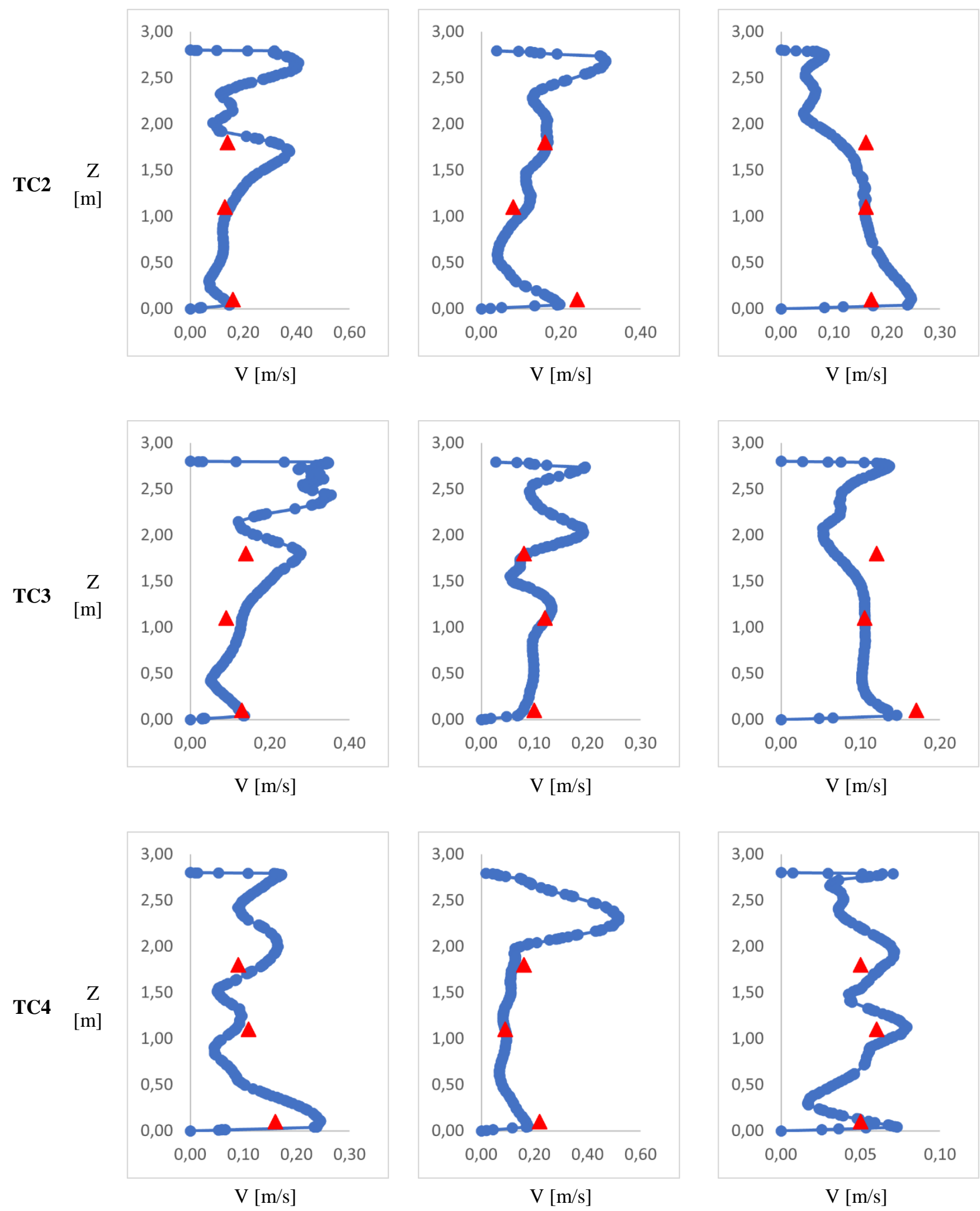

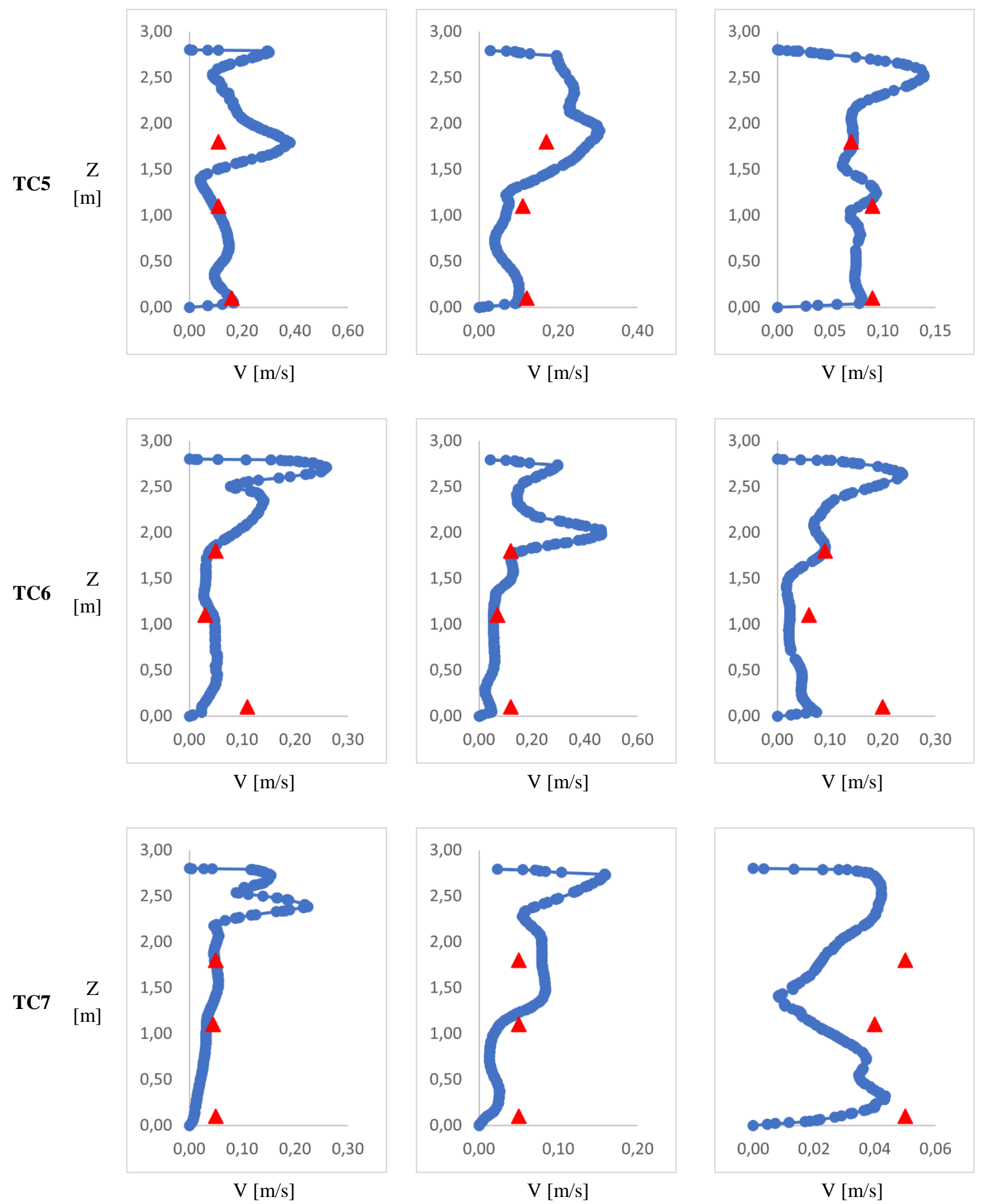

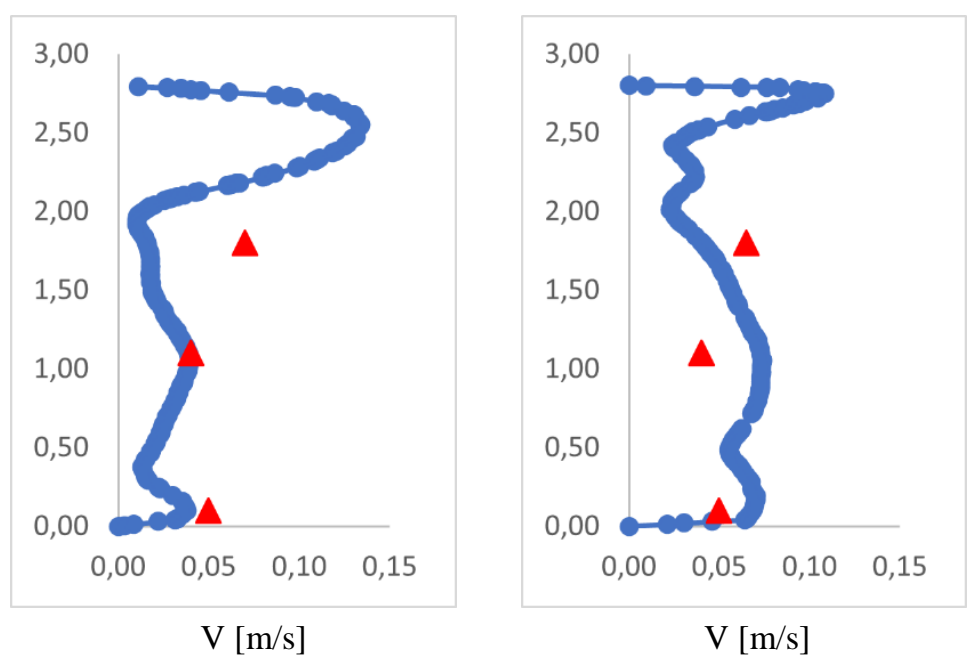

Figure 12 - Calculated air velocity magnitudes vs. measurements $(\mathrm{m} / \mathrm{s})$

\subsection{Temperature calculations}

Figure $13(a, b)$ shows the strong dependence of the temperature field on the flow field and viceversa. Among the experimental imagines, the temperature is sufficiently uniform for all the cases. The cooling tests reached values from the $24-25{ }^{\circ} \mathrm{C}$ up to the $26{ }^{\circ} \mathrm{C}$ (TC3). The heating one, instead, registers $22{ }^{\circ} \mathrm{C}$ for the case TC7 and $21.4{ }^{\circ} \mathrm{C}$ for the test TC8. The uniformity is also extended in the vertical plans (form the floor to the ceiling) for all the cases. Moreover, a slight temperature increase in the lower zone is evident (Figure 13), corresponding to the warm wall position. This observation is valid only for heating tests. Thanks to the temperature data of the experimental campaigns, the INDULINE diffuser aims to provide not only a uniform fluid dynamic filed but also a temperature one, to guarantee the indoor comfort. Data of the temperature located in the measured points is obtained using interpolation procedures. 
Scale $[\mathrm{m} / \mathrm{s}]$
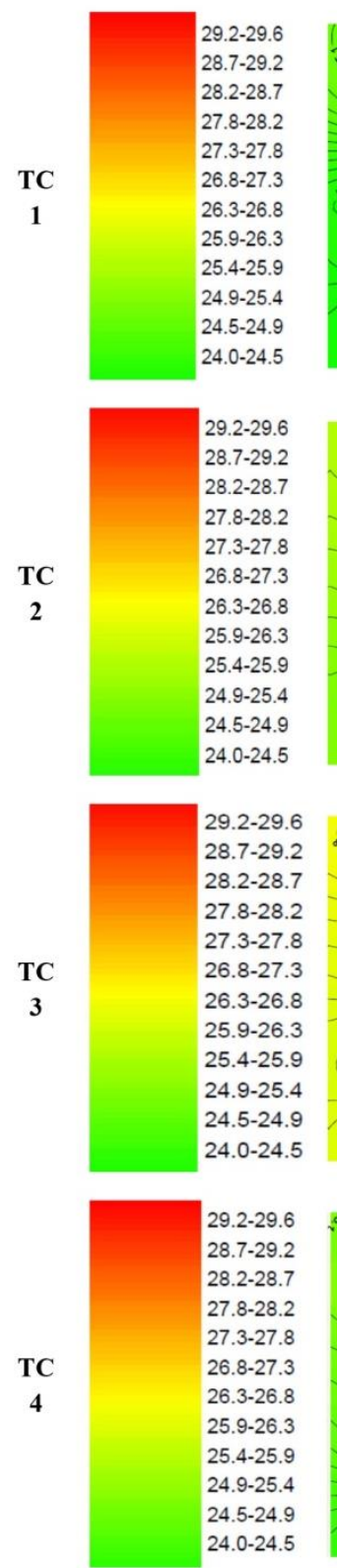

$\mathbf{H}=\mathbf{0 . 1} \mathbf{m}$
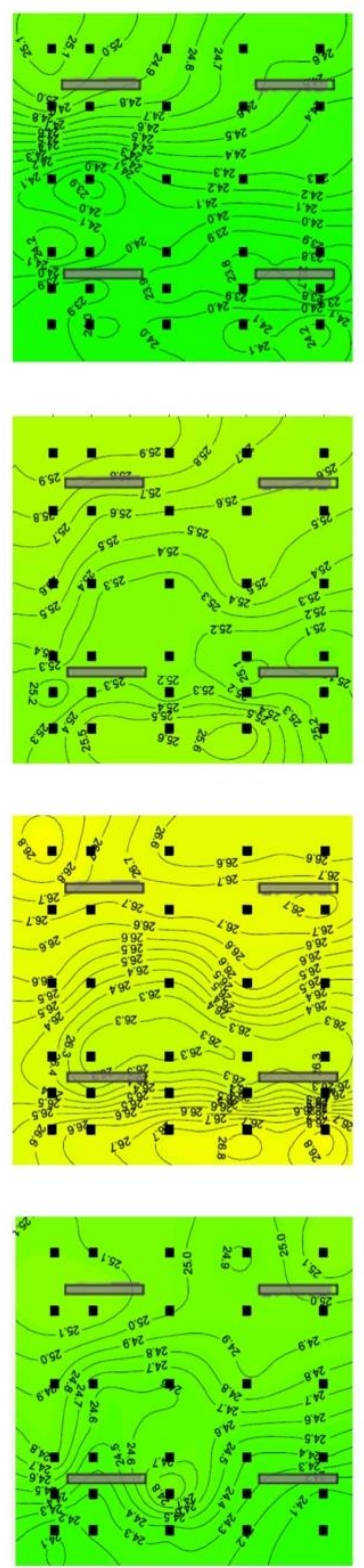

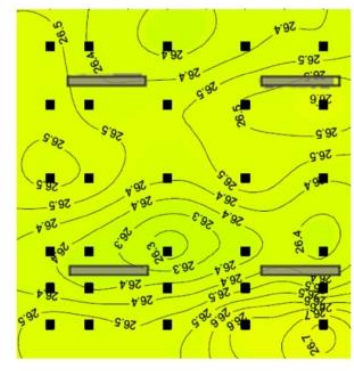

$\mathrm{H}=1.1 \mathrm{~m}$
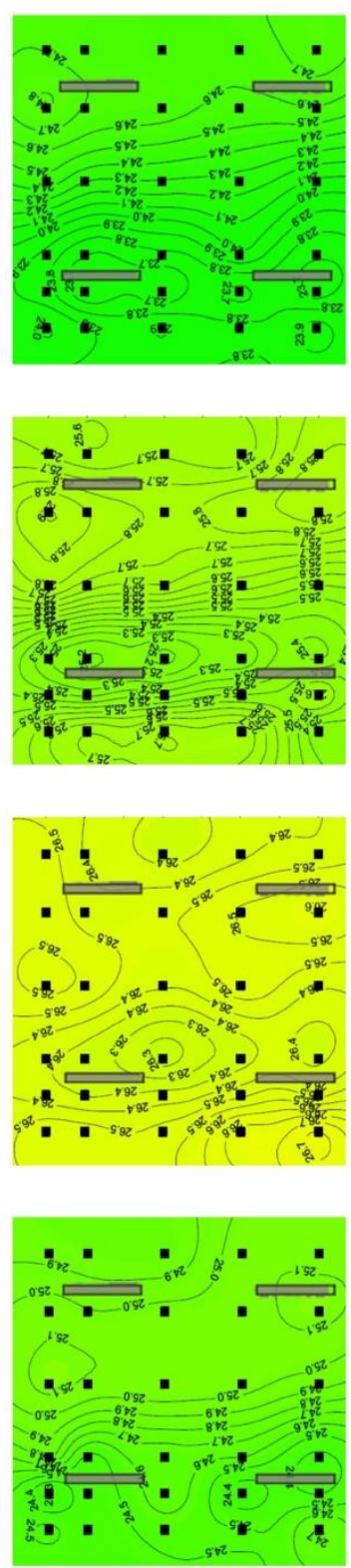

$H=1.8 \mathrm{~m}$
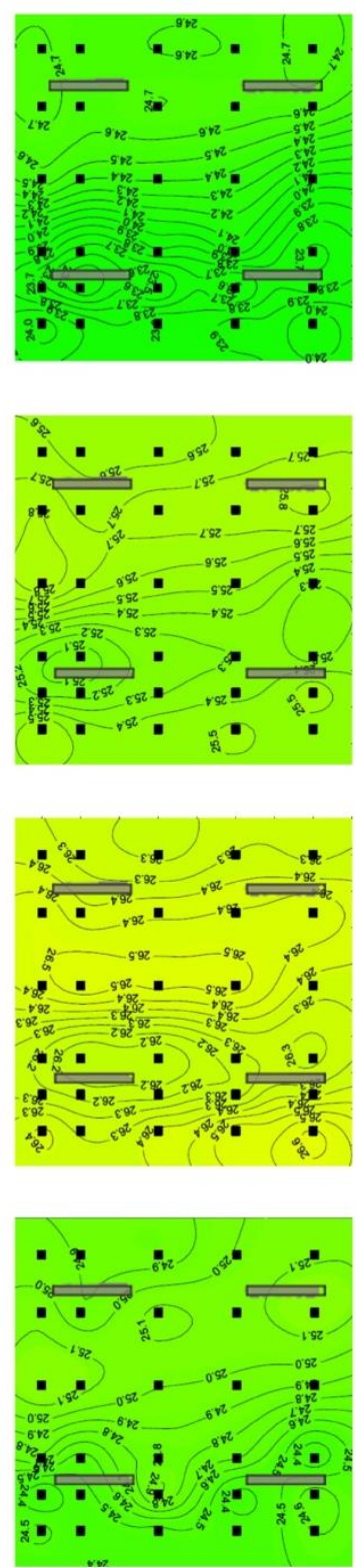

a) 
Numerical data of the temperature, elaborated with the CFD, comply with the experimental tests data (Figure14).

The temperature is uniform in the entire field varying the height to the floor $(0.1,1.1$ and $1.80 \mathrm{~m})$ as it is showed in the numerical simulations (Figure 14). Due to the phenomena of the temperature recirculation near the inlet diffusers, there are fairly slight deviations about $\pm 0.5{ }^{\circ} \mathrm{C}$, but this range is marginally considerable. This fact is the consequence of the interaction between the flowing air descending from the diffusers with the convective one created by the warm wall. It can also notice the role of the hot facade able to create those high-temperature zones. Moreover, the numerical simulations help to highlight netter this issue compared to the experimental data. 
1

2

3

4

5

6

7

8

9

10

11

12

13

14

15

16

17

18

19

20

21

22

23

24

25

26

27

28

29

30

31

32

33

34

35

36

37

38

39

40

41

42

43

44

45

46

47

48

49

50

51

52

53

54

55

56

57

58

59

60

61

62

63

64

65
Scale

$\left[{ }^{\circ} \mathbf{C}\right]$
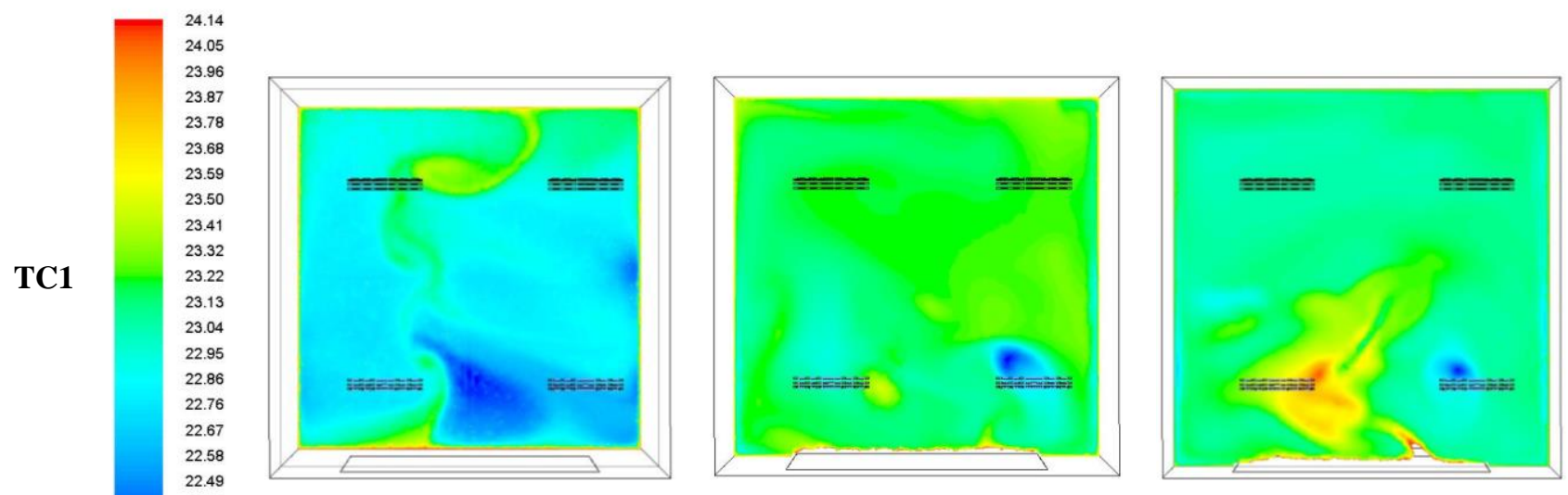

TC2
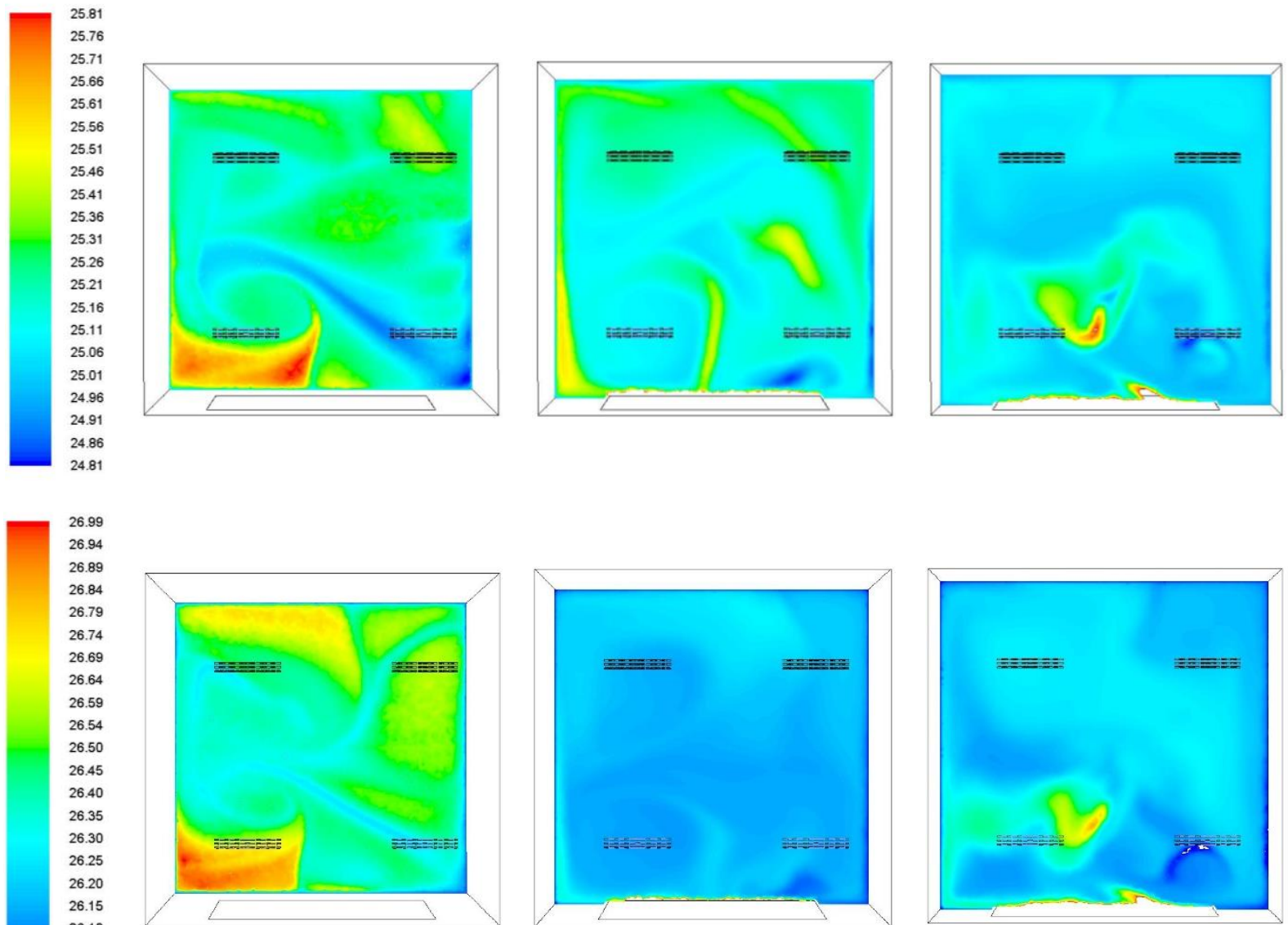


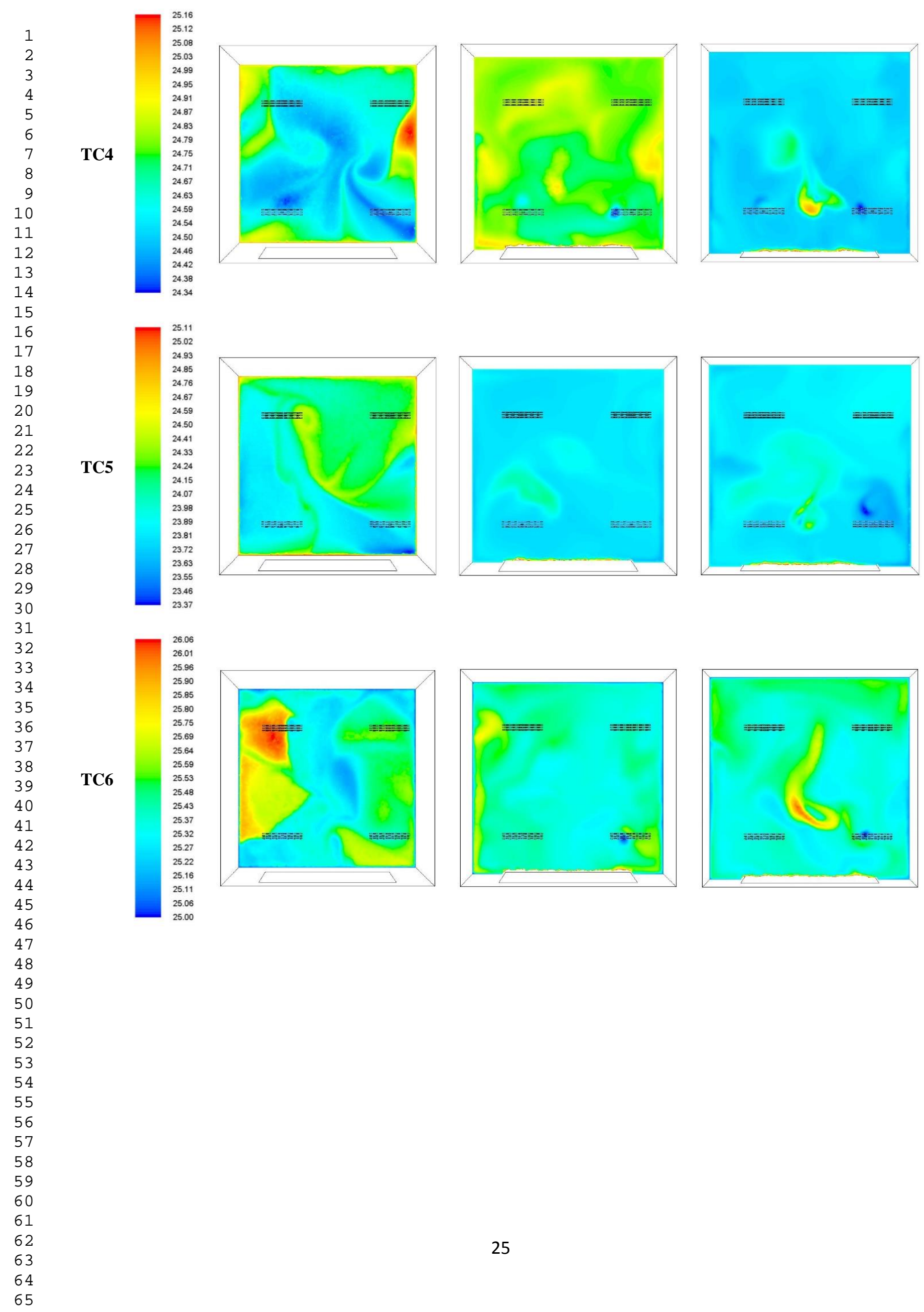



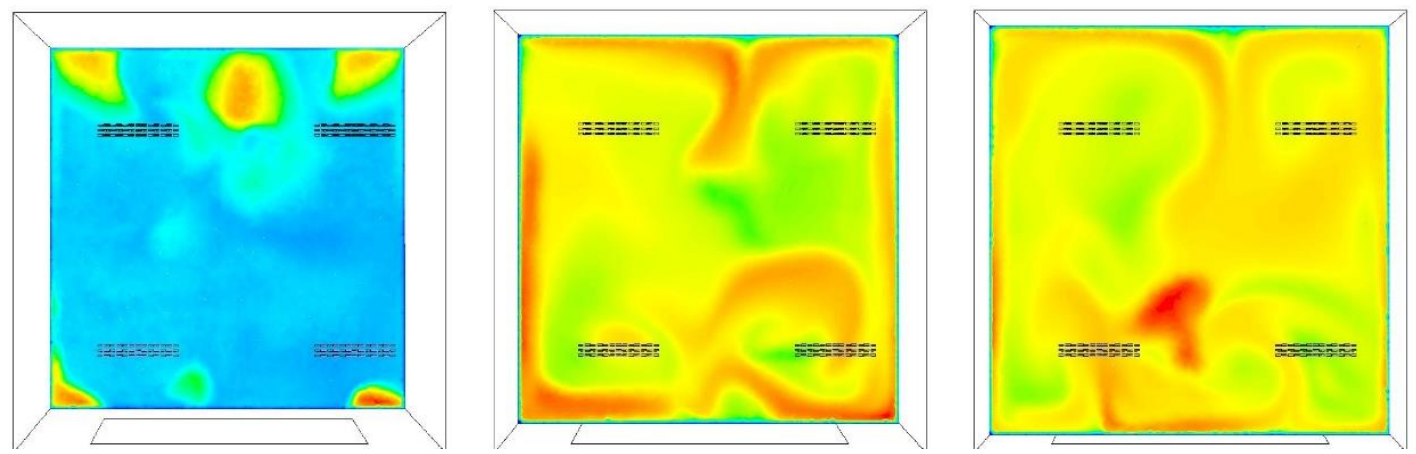

TC8
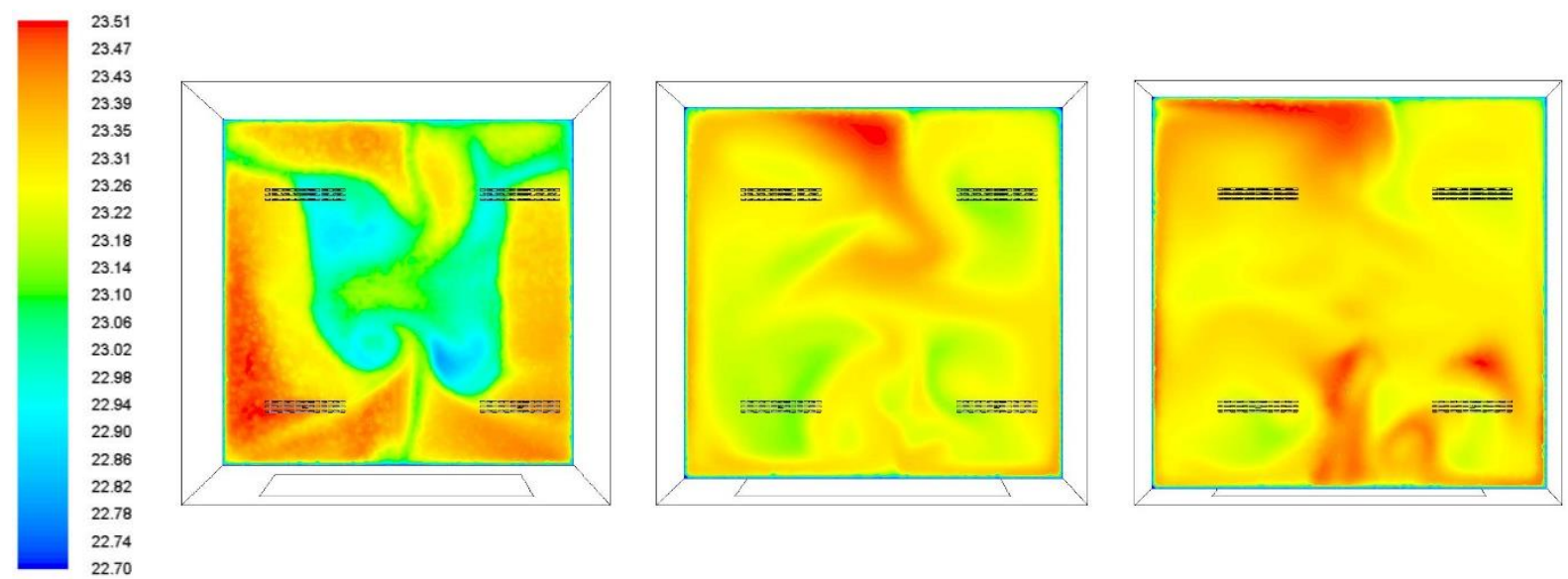

Figure 14 - Temperature contours at height 0.1, 1.1, $1.8 \mathrm{~m}$ from the ground

Figure 15-16 represent the temperature vectors and contours located in a plane passing in the inlet air diffusers and parallel to the warm wall. As previously done for the velocity analysis, Test Case 1 and Test Case 8 are chosen for cooling and heating, respectively. The imagines, extracted from the planes, show a uniform distribution in term of the temperature inside the room test, until a specific height. The highest zone is characterized by the conjunction of the air blast and natural convection, giving back a warmer air. Observing both the temperature and velocity field, the air velocity, close to the inlet diffusers, is higher due to the convective currents. On the other hand, the uniformity of those parameters (temperature and velocity) is guaranteed by the INDULINE diffuser, except for the aforementioned zone. Moreover, the space located near the ceiling is not relevant to the occupants. 


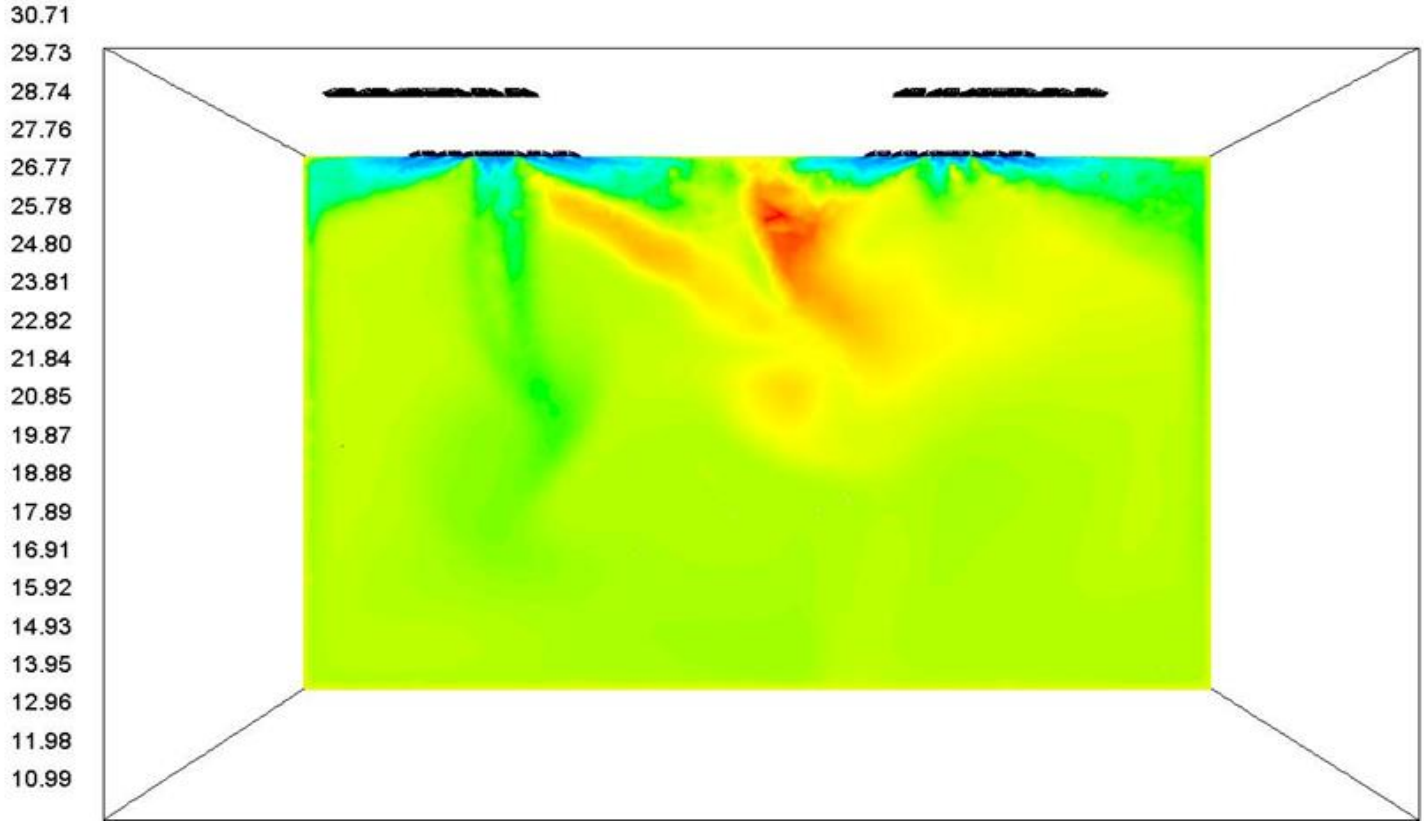

Figure 15 - Temperature contours Test Case 1 - Plane $x=0.85 \mathrm{~m}, y=1.05 \mathrm{~m}$
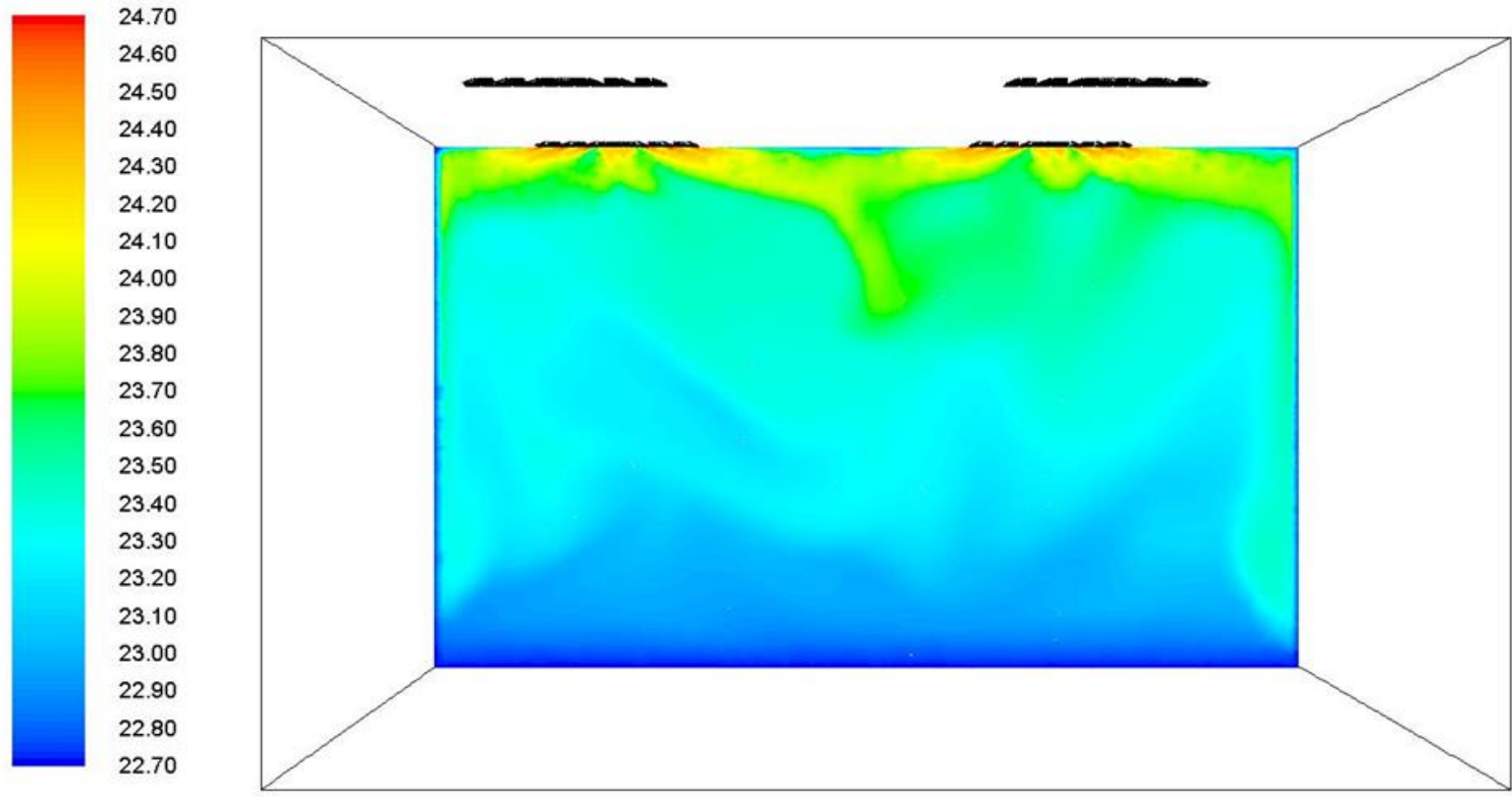

Figure 16 - Temperature contours Test Case 8 - Plane $x=0.85 \mathrm{~m}, y=1.05 \mathrm{~m}$

Moving to Figure 17, a comparison between experimental data and numerical simulation results are reported along the chosen vertical line passing through:

- the centre of the room $(x=1.5 \mathrm{~m}, \mathrm{y}=1.3 \mathrm{~m})$;

- the inlet air diffuser $(x=2.5 \mathrm{~m}, \mathrm{y}=2.3 \mathrm{~m})$;

- the recovery air diffuser $(x=3.5 \mathrm{~m}, \mathrm{y}=3.8 \mathrm{~m})$; 
As aforementioned, the blue points represent the numerical data, and the red triangles are the experimental data. Among the temperature analysis, the numerical and experimental results are in line. In this case, the uniformity of the field is more evident compared to the velocity analysis, varying also the height. According to this, the numerical curves are constant, describing the trends from the floor up to the ceiling. Air currents, therefore, are under control, providing the correct temperature head-foot comfort for the occupants. This consideration is valid not only for the case having minimum airflow (TC6) but for the maximum air mass too (TC1, TC7, TC8). Moreover, this analysis confirms the accuracy of the numerical simulations to the experimental campaigns. Analysing the velocity and temperature deviations of the TC1 and TC 2 cases, the velocity obtains a maximum value of $5 \%$ compared to the $1 \%$ of the temperature, with an average percentage error of $0.2 \%$. TC3 and TC4 cases are the most critical also for the temperature scenario. Moving to the TC5, Figure 4 reported the air recirculation phenomena in the centre of the room, highlighting the relevant deviations. On the other hand, the percentage error is decreasing $(0.1 \%)$ in the vicinity of inlet and recovery air diffusers, showing the correspondence between the two methods. Same assumptions could be made for the TC6, even though there is a considerable difference between supply air temperature and the room temperature.

Lastly, the TC7 and TC8 tests, the heating one, register an error of 1\%, providing differences higher than the cooling cases. Therefore, the high value of the velocity error showed in Figure 12 is due to the accuracy of the anemometers used.
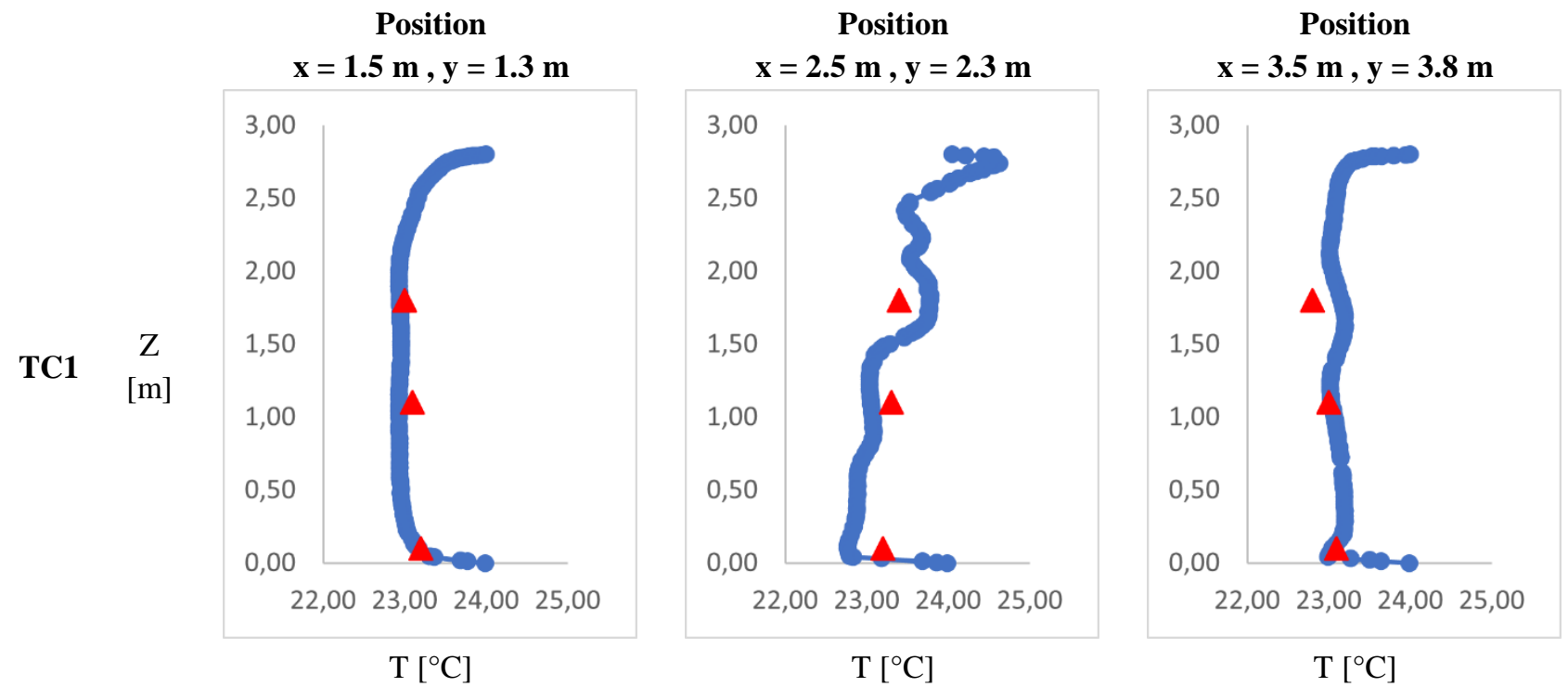
1

2

3

4

5

6

7

8

9

10

11

12

13

14

15

16

17

18

19

20

21

22

23

24

25

26

27

28

29

30

31

32

33

34

35

36

37

38

39

40

41

42

43

44

45

46

47

48

49

50

51

52

53

54

55

56

57

58

59

60

61

62

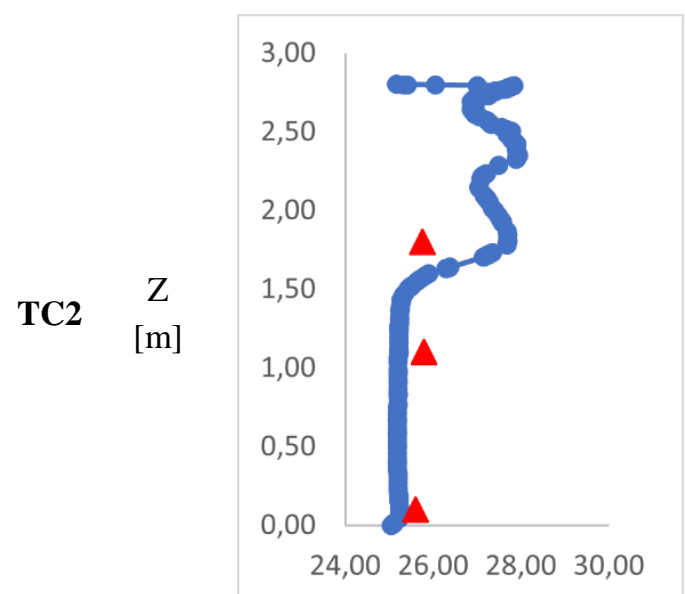

$\mathrm{T}\left[{ }^{\circ} \mathrm{C}\right]$

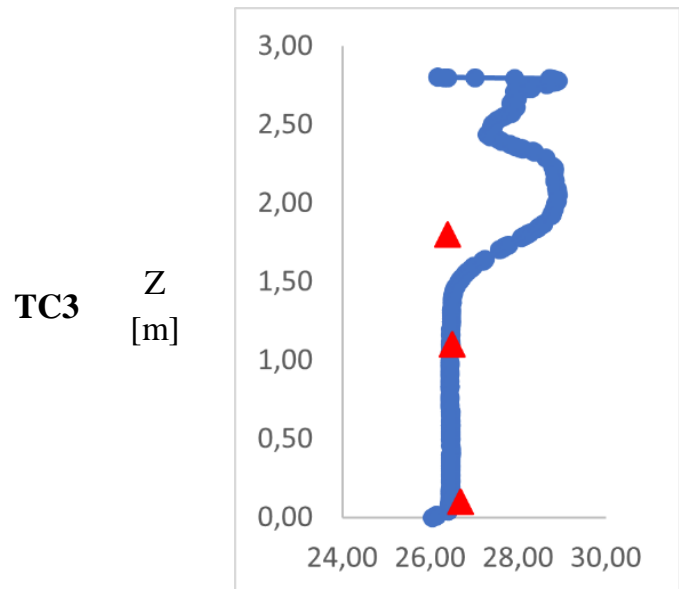

$\mathrm{T}\left[{ }^{\circ} \mathrm{C}\right]$

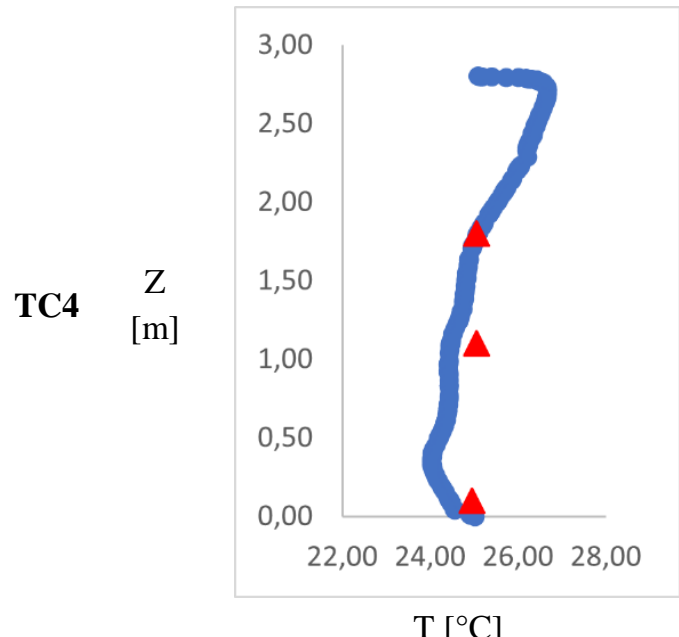

$\mathrm{T}\left[{ }^{\circ} \mathrm{C}\right]$
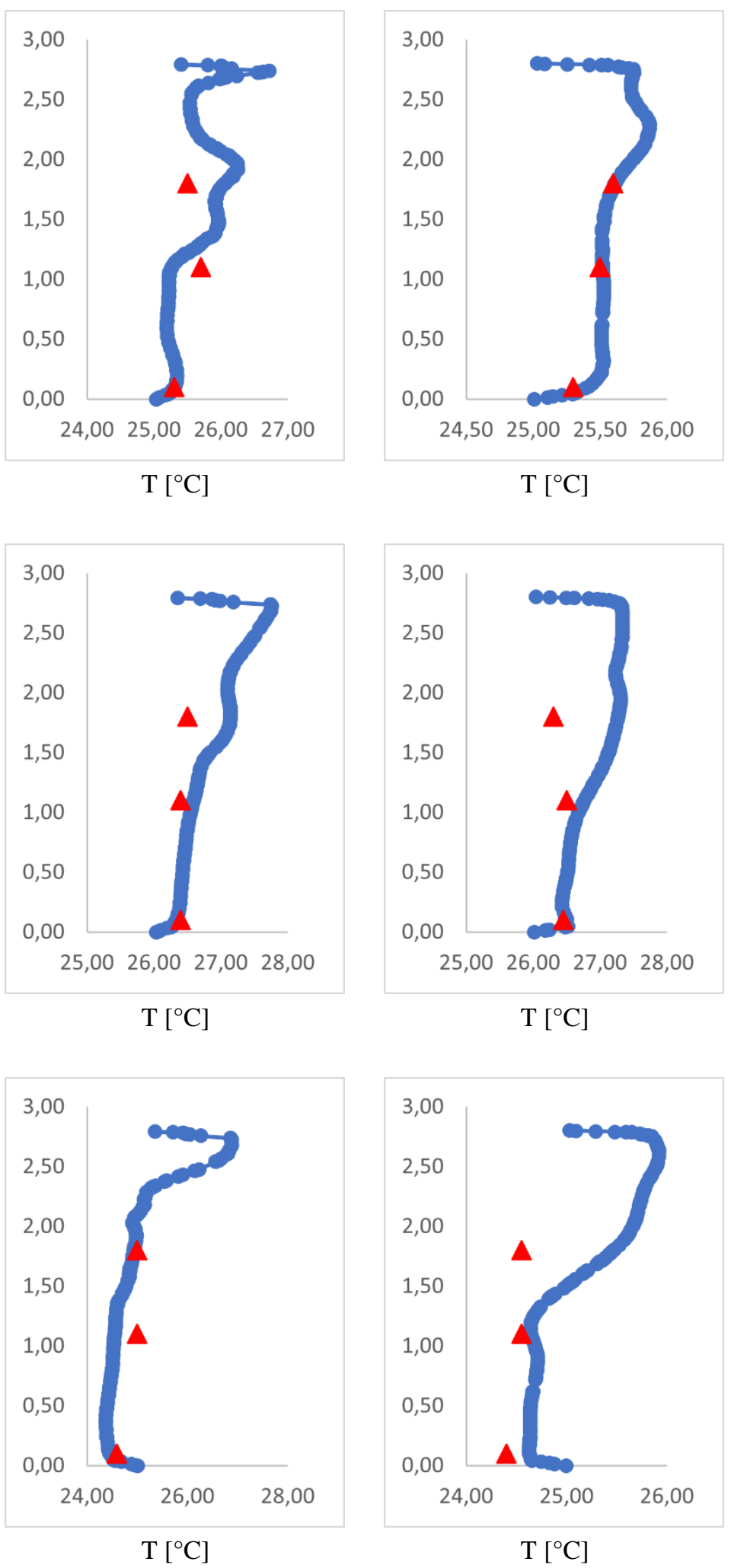
1

2

3

4

5

6

7

8

9

10

11

12

13

14

15

16

17

18

19

20

21

22

23

24

25

26

27

28

29

30

31

32

33

34

35

36

37

38

39

40

41

42

43

44

45

46

47

48

49

50

51

52

53

54

55

56

57

58

59

60

61

62

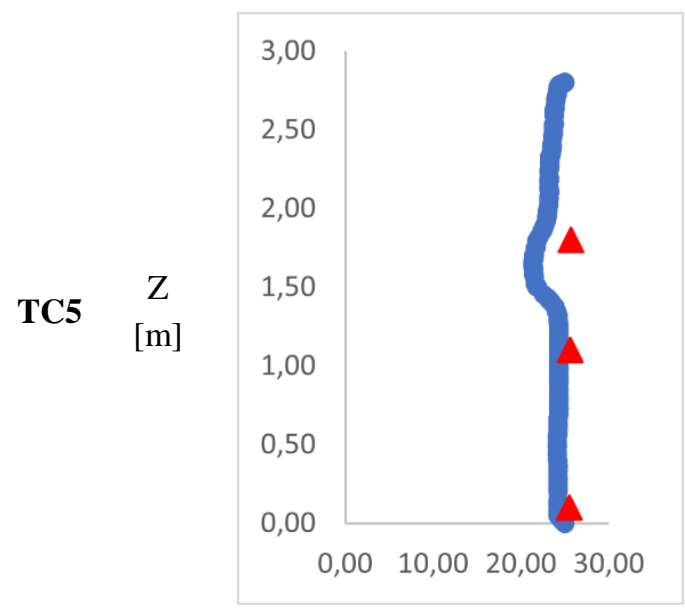

$\mathrm{T}\left[{ }^{\circ} \mathrm{C}\right]$

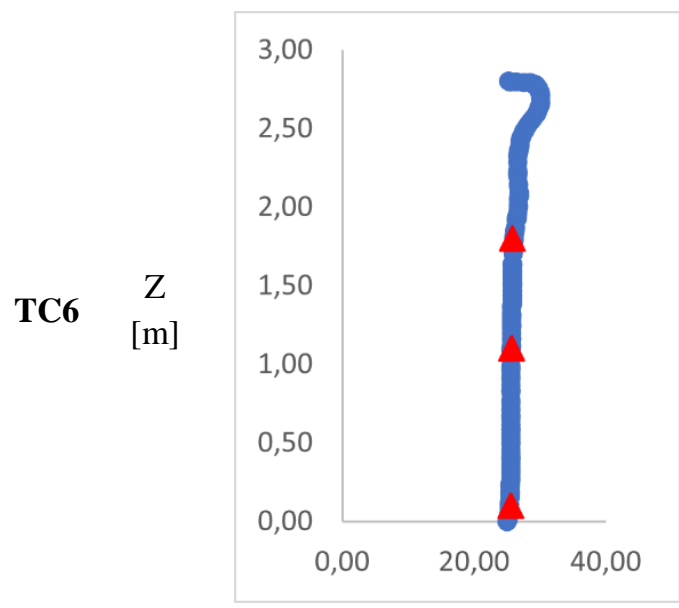

$\mathrm{T}\left[{ }^{\circ} \mathrm{C}\right]$

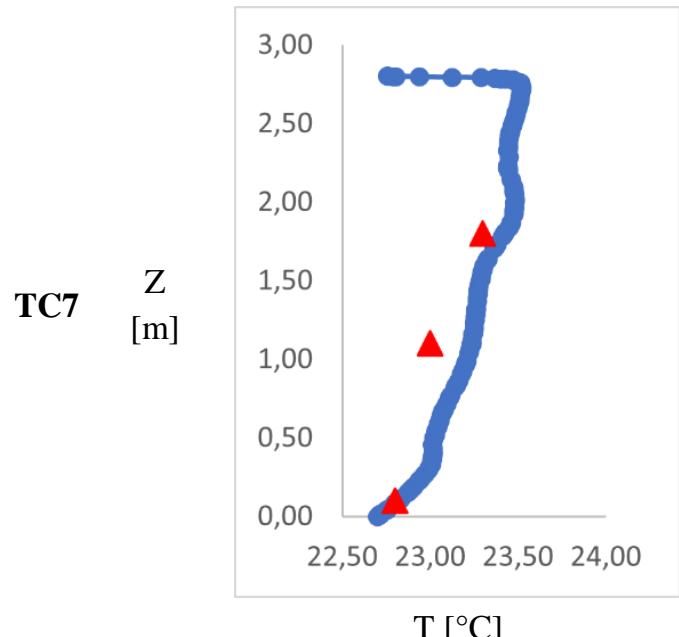

$\mathrm{T}\left[{ }^{\circ} \mathrm{C}\right]$

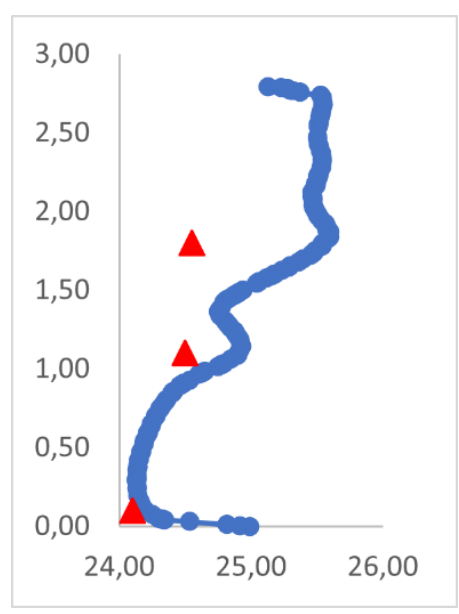

$\mathrm{T}\left[{ }^{\circ} \mathrm{C}\right]$

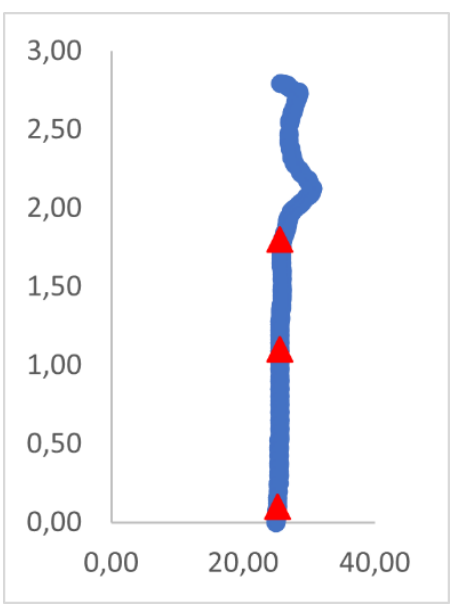

$\mathrm{T}\left[{ }^{\circ} \mathrm{C}\right]$

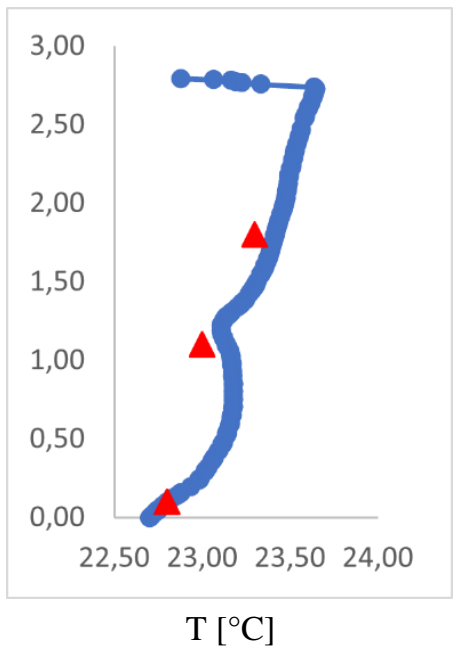

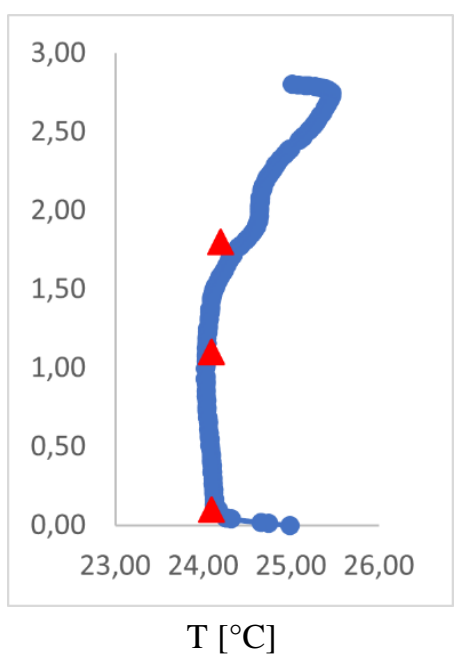
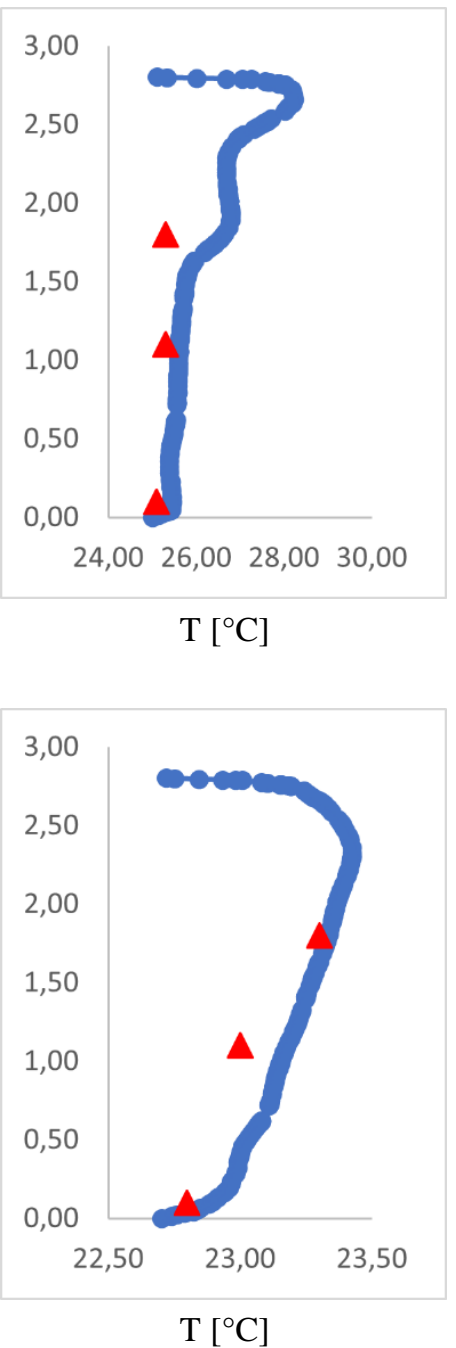


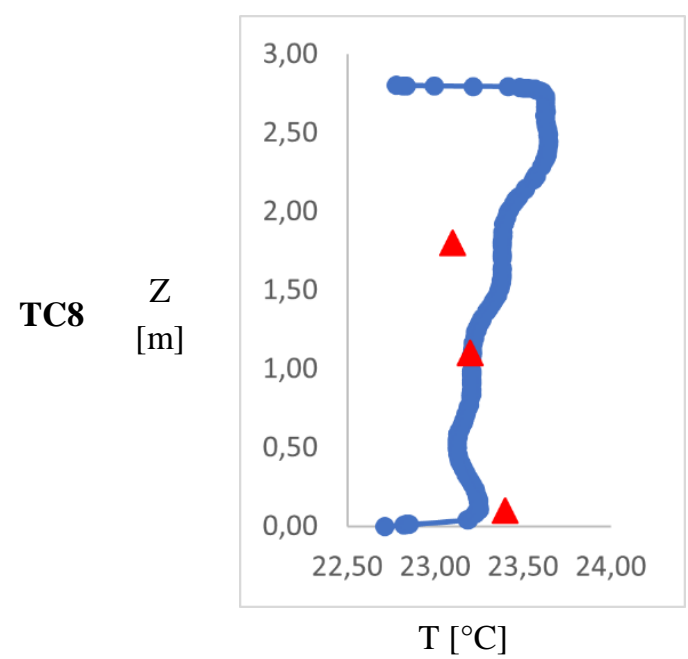

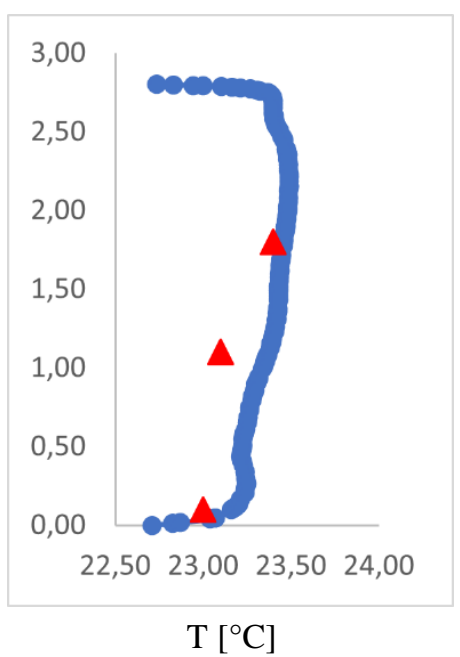

Figure 17 - Calculated air temperature vs. measurements $\left({ }^{\circ} \mathrm{C}\right)$

\section{Conclusions}

The current work aims to analyze the performance of an air swirl diffuser, named INDULINE. It is a linear wall diffuser with a variable mass flow. This competitive system is characterized by one or two rows of micro spot diffusers with also a rectangular shape and arranged vertically. This configuration allows to guarantee the proper indoor comfort for the occupant combined with its functioning. Varying its mass flow rate for each side of the diffuser, the improvement in terms of indoor comfort is evident.

Two methods, the campaigns measurements and the numerical simulation CFD (convection and radiation) allow the authors to develop this study.

During the first phase, the realization of a thermal indoor environment is necessary to carry on the experimental measurements. Thirty sensors are positioned inside the room test to cover the entire space at the following height form the floor: $0.1,1.1,1.8 \mathrm{~m}$. Then, the installation of a warm wall is chosen as the heating system. Several tests were carries out, six for cooling and two for heating with different volumetric air rate and supply air temperature of the diffusers. Also, the warm wall thermal loads are considered.

The experimental data were reproduced with the CFD to analyzed also some point unreachable to the sensors. Once the experimental and numerical results are confirmed, the CFD allows studying the global behavior of the thermal fluid dynamic field inside the room. The experimental results show that INDULINE diffuser can guarantee the velocity uniformity of the air both for vertical and transversal planes at different heights. it reaches therefore the proper comfort of the occupants. On the other hand, the numerical analysis highlights the presence of the air mass currents, due to the natural convection. However, those air currents do not compromise indoor comfort.

Comparing the experimental and numerical results of the velocity, it is evident the reliability of the two methods, providing a maximum error of 5\% for TC1-TC2 and 7\% for TC3-TC4, always in the vicinity of the recovery diffusers. The other positions error is above $2 \%$. More in details, high differences can be noticed for the case TC5 at the height of $1.8 \mathrm{~m}$ and TC6 (an error equal to 10\%) 
due to the higher deviations between supply air temperature e la room temperature that generates intense convective currents. The heating cases, TC7 and TC8, the error is lower $(0.5 \%)$, located near the inlet diffusers, but it increased to $40 \%$ in correspondence to the recovery ones. This fact is connected to the velocity anemometers used in the measurement's campaigns. They are not able to register the low speed of the TC7 and TC8 cases.

Moving to the temperature analysis, experimental and numerical results showed the uniformity of the temperature field. As previously done for the velocity parameter, the percentage error is still under control. More in details, the maximum deviation of TC1-TC2 is around 1\% with an average percentage error of $0.2 \%$. Two cases, TC3 and TC4, were almost critical, wherein the temperature difference was around 1\% between the numerical and experimental results. TC5 and TC6 showed consistent deviation located in the center of the room. On the other hand, this error is decreased $(0.1 \%)$ near the inlet and recovery air diffusers. Lastly, the heating TC7 and TC8 reported higher values than the cooling cases, but always around $1 \%$.

Future developments will involve the humidity analysis, always using the experimental data and the numerical one. As it is well-known, a healthy and comfortable area for inhabitants is not easy to get in terms of velocity, temperature and relative humidity, being a fragile balance of them. In this balance, many factors are taken into account, wherein the relative humidity could have an impacted role, due to its influence on the heat and cold human perceptions.

\section{Acknowledgments}

We thank the company Kiefer for providing the data of the experimental tests, commissioned by the company SAGICOFIM S.p.a., as part of the ERNEST \& YOUNG MILANO project. 


\section{References}

ANSYS (2013). Inc. ANSYS manual, Release 14.5.

Ascione F, Bellia L, Capozzoli A (2013). A coupled numerical approach on museum air conditioning: Energy and fluid-dynamic analysis. Applied Energy, 103: 416-427.

Aziz MA, Gad IAM, Mohammed ESFA, Mohammed RH (2012). Experimental and numerical study of influence of air ceiling diffusers on room air flow characteristics. Energy and Buildings, 55: 738-746.

Chen Q (1999). Comparison of different $\mathrm{k}-\varepsilon$ models for indoor airflow computations. Part B, Fundamentals Numerical Heat Transfer, 28 (3): 353-369.

Chen YJ, Norford LK, Samuelson HW, Malkawi A (2018). Optimal control of HVAC and window systems for natural ventilation through reinforcement learning. Energy and Buildings, 169: 195205 .

Cheong KWD, Djunaedy E, Chua YL, Tham KW, Sekhar SC, Wong NH, Ullah MB (2003). Thermal comfort study of an air-conditioned lecture theatre in the tropics. Building and Environment, 38 (1): 63-73.

Dai YC, Jiang ZY, Shen Q, Chen PZ, Wang SG, Jiang Y (2016). A decentralized algorithm for optimal distribution in HVAC systems. Building and Environment, 95: 21-31.

Fong KF, Hanby VI, Chow TT (2011). A Robust Evolutionary Algorithm for HVAC Engineering Optimization. Journal HVAC\&R Research, 14 (5): 683-705.

Gao R, Liu K, Li A, Fang Z, Yang Z, Cong B (2018). Study of the shape optimization of a tee guide vane in a ventilation and air-conditioning duct. Building and Environment, 132: 345-356.

Gärtner JA, Gray FM, Auer T (2020). Assessment of the impact of HVAC system configuration and control zoning on thermal comfort and energy efficiency in flexible office spaces. Energy and Buildings, 212: https://doi.org/10.1016/j.enbuild.2020.109785.

Gebremedhin KG, Wu BX (2003). Characterization of flow field in a ventilated space and simulation of heat exchange between cows and their environment. Journal of Thermal Biology, 28 (4): 301-319.

Habitzreuter L, Smith ST, Keeling T (2020). Modelling the overheating risk in an uniform high-rise building design with a consideration of urban context and heatwaves. Indoor and Build environment, 29 (5): 671-688.

INDULINE data sheet source https://www.sagicofim.com/prodotti/induline/. Accessed 02 August 2021.

Issa RI (1986). Solution of Implicitly Discretized Fluid Flow Equations by Operator Splitting. Journal of Computational Physics, 62: 40-65.

Jaszczur M, Branny M, Karch M, Borowski M (2016). Experimental analysis of the velocity field of the air flowing through the swirl diffusers. Journal of Physics Conference proceeding, 745 (3): 19. 
Jiang P (2011). Analysis of national and local energy-efficiency design standards in the public building sector in China. Energy for Sustainable Development, 15: 443-450.

Jorens S, Verhaert I, Sörensen K (2018). Design optimization of air distribution systems in nonresidential buildings. Energy and Buildings, 175: 48-56.

Junga W, Jazizadehb F (2019). Human-in-the-loop HVAC operations: A quantitative review on occupancy, comfort, and energy-efficiency dimensions. Applied Energy, 239: 1471-1508.

Kima G, Schaefer L, Limc TS, Kima JT (2013). Thermal comfort prediction of an underfloor air distribution system in a large indoor environment. Energy and Buildings, 64: 323-331.

Kovacs GH, Belusko M, Pockett J, Boland J (2018). Heat stress-resistant building design in the Australian context. Energy and Buildings, 158: 290-299.

Launder BE, Spalding DP (1972). Mathematical models of turbulence. Academic Press, New York.

Li HR, Li XF (2018). Benchmarking energy performance for cooling in large commercial buildings. Energy and Buildings, 176: 179-193.

Li W, Koob C, Hongc T, Oh J, Chad SH, Wang S (2020). A novel operation approach for the energy efficiency improvement of the HVAC system in office spaces through real-time big data analytics. Renewable and Sustainable Energy Reviews, 127: https://doi.org/10.1016/j.rser.2020.109885.

Li XT, Shen C, Yu CWF (2017). Building energy efficiency: Passive technology or active technology? Indoor and Built Environment, 26: 729-732.

Manuel MCE, Lin PT, Chang M (2018). Optimal duct layout for HVAC using topology optimization. Science and Technology for the Built Environment, 24 (3): 212-219.

Muthers S, Laschewski G, Matzarakis A (2017). The Summers 2003 and 2015 in South-West Germany: Heat Waves and Heat-Related Mortality in the Context of Climate Change. Atmosphere, 8 (11): 1-13.

Pandey R, Rao AK, Yadav V (2015). Comparison between simulation and experimental technique inside an air conditioned room to analyze the performance and flow characteristics of ceiling swirl diffuser under different operating and flow parameters. International journal of engineering sciences \& research Technology, 4 (11): 424-431.

Ren C, Cao SJ (2019). Development and application of linear ventilation and temperature models for indoor environmental prediction and HVAC systems control. Sustainable Cities and Society, 51: https://doi.org/10.1016/j.scs.2019.101673.

Rouaud O, Havet M (2002). Computation of the airflow in a pilot scale clean room using $\mathrm{k}-\varepsilon$ turbulence models. International Journal of Refrigeration, 25 (3): 351-361.

Stamou A, Katsiris I (2006). Verification of a CFD model for indoor airflow and heat transfer. Building and Environment, 41: 1171-1181. 
Tacutu L, Nastase I, Bode F, Croitoru C, Lungu C (2019). Numerical models development for unidirectional air flow diffusers with lobed and circular orifices. E3S Web of conferences (CLIMA 2019), 111: 1-8.

Tan J, Zheng Y, Tang X, Guo C, Li L, Song G, Zhen X, Yuan D, Kalkstein AJ, Li F, Chen H (2009). The urban heat island and its impact on heat waves and human health in Shanghai. International Journal of Biometeorology, 54 (1): 75-84.

UNI EN ISO 7730 (2006). Ergonomics of the thermal environment-Analytical determination and interpretation of thermal comfort using calculation of the PMV and PPD indices and local thermal comfort criteria.

Wei Che W, Yan Tso C, Sun L, Ip DYK, Lee H, Chao CYH, Lau AKH (2019). Energy consumption, indoor thermal comfort and air quality in a commercial office with retrofitted heat, ventilation and air conditioning (HVAC) system. Energy and Buildings, 201: 202-215.

Zhang S, Lin Z, Ai ZT, Huan C, Cheng Y, Wang F (2019). Multi-criteria performance optimization for operation of stratum ventilation under heating mode. Applied Energy, 239: 969-980.

Zinzi M, Carnielo E, Mattoni B (2018). On the relation between urban climate and energy performance of buildings. A three-years experience in Rome, Italy. Applied Energy, 221 (1): 148160. 